\title{
Electronic Structure and Properties of Berkelium lodates
}

Mark A. Silver, ${ }^{\dagger}$ Samantha K. Cary, ${ }^{\dagger}$ Alejandro J. Garza, ${ }^{\dagger}$ Ryan E. Baumbach, ${ }^{\S}$ Alexandra A. Arico, ${ }^{\dagger}$ Gregory A. Galmin, ${ }^{\dagger}$ Kuan-Wen Chen, ${ }^{\S}$ Jason A. Johnson, ${ }^{\|}$Jamie C. Wang, ${ }^{\dagger}$ Ronald J. Clark, Alexander Chemey, ${ }^{\dagger}$ Teresa M. Eaton, ${ }^{\dagger}$ Matthew L. Marsh, ${ }^{\dagger}$ Kevin Seidler, ${ }^{\dagger}$ Shane S. Galley, ${ }^{\dagger}$ Lambertus van de Burgt, ${ }^{\dagger}$ Ashley L. Gray, ${ }^{\|}$David E. Hobart, ${ }^{\dagger}$ Kenneth Hanson, ${ }^{\dagger}$ Shelley M. Van Cleve, ${ }^{\perp}$

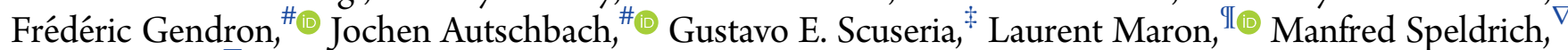
Paul Kögerler, ${ }^{\nabla}{ }^{(0}$ Cristian Celis-Barros, ${ }^{\otimes}{ }^{(0)}$ Dayán Páez-Hernández, ${ }^{\otimes}{ }^{\circledR}$ Ramiro Arratia-Pérez, ${ }^{\otimes}$ Michael Ruf, and Thomas E. Albrecht-Schmitt* $* \dagger \odot$

${ }^{\dagger}$ Department of Chemistry and Biochemistry, Florida State University, Tallahassee, Florida 32306, United States

${ }^{\ddagger}$ Department of Chemistry, Rice University, Houston, Texas 77251, United States

${ }^{\S}$ National High Magnetic Field Laboratory, Tallahassee, Florida 32310, United States

"Environmental Health and Safety, Florida State University, Tallahassee, Florida 32306, United States

${ }^{\perp}$ Nuclear Materials Processing Group, Oak Ridge National Laboratory, One Bethel Valley Road, Oak Ridge, Tennessee 37830 , United States

\# Department of Chemistry, University at Buffalo, State University of New York, Buffalo, New York 14260, United States

II Laboratorie de Physique et Chimie des Nano-objets, Institut National des Sciences Appliquées, 31077 Toulouse Cedex 4, France

${ }^{\nabla}$ Institut für Anorganische Chemie, RWTH Aachen University, D-52074 Aachen, Germany

${ }^{\otimes}$ Centro de Nanociencias Aplicadas, Facultad de Ciencias Exactas, Universidad Andrés Bello, República 275, Santiago, Chile

Bruker AXS, 5465 East Cheryl Parkway, Madison, Wisconsin 53711, United States

\section{Supporting Information}

ABSTRACT: The reaction of ${ }^{249} \mathrm{Bk}(\mathrm{OH})_{4}$ with iodate under hydrothermal conditions results in the formation of $\mathrm{Bk}\left(\mathrm{IO}_{3}\right)_{3}$ as the major product with trace amounts of $\mathrm{Bk}\left(\mathrm{IO}_{3}\right)_{4}$ also crystallizing from the reaction mixture. The structure of $\mathrm{Bk}\left(\mathrm{IO}_{3}\right)_{3}$ consists of nine-coordinate $\mathrm{Bk}^{\mathrm{III}}$ cations that are bridged by iodate anions to yield layers that are isomorphous with those found for $\mathrm{Am}^{\mathrm{III}}, \mathrm{Cf}^{\mathrm{III}}$, and with lanthanides that possess similar ionic radii. $\mathrm{Bk}\left(\mathrm{IO}_{3}\right)_{4}$ was expected to adopt the same structure as $\mathrm{M}\left(\mathrm{IO}_{3}\right)_{4}(\mathrm{M}=\mathrm{Ce}, \mathrm{Np}, \mathrm{Pu})$, but instead parallels the structural chemistry of the smaller $\mathrm{Zr}^{\mathrm{IV}}$ cation. $\mathrm{Bk}^{\mathrm{III}}-\mathrm{O}$ and $\mathrm{Bk}^{\mathrm{IV}}-\mathrm{O}$ bond lengths are shorter than anticipated and provide further support for a postcurium break in the actinide series. Photoluminescence and

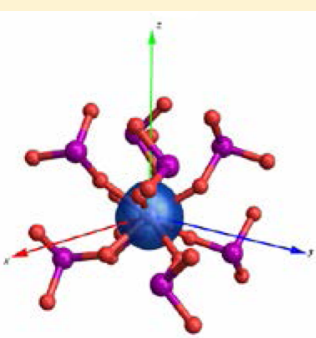

$\mathrm{Bk}\left(\mathrm{IO}_{3}\right)_{4}$

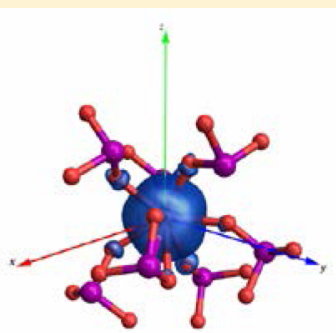

$\mathrm{Bk}\left(\mathrm{IO}_{2}\right)_{2}$ absorption spectra collected from single crystals of $\mathrm{Bk}\left(\mathrm{IO}_{3}\right)_{4}$ show evidence for doping with $\mathrm{Bk}^{\mathrm{III}}$ in these crystals. In addition to luminescence from $\mathrm{Bk}^{\mathrm{III}}$ in the $\mathrm{Bk}\left(\mathrm{IO}_{3}\right)_{4}$ crystals, a broad-band absorption feature is initially present that is similar to features observed in systems with intervalence charge transfer. However, the high-specific activity of ${ }^{249} \mathrm{Bk}\left(t_{1 / 2}=320 \mathrm{~d}\right)$ causes oxidation of $\mathrm{Bk}^{\mathrm{III}}$ and only $\mathrm{Bk}^{\mathrm{IV}}$ is present after a few days with concomitant loss of both the $\mathrm{Bk}^{\mathrm{III}}$ luminescence and the broadband feature. The electronic structure of $\mathrm{Bk}\left(\mathrm{IO}_{3}\right)_{3}$ and $\mathrm{Bk}\left(\mathrm{IO}_{3}\right)_{4}$ were examined using a range of computational methods that include density functional theory both on clusters and on periodic structures, relativistic $a b$ initio wave function calculations that incorporate spin-orbit coupling (CASSCF), and by a full-model Hamiltonian with spin-orbit coupling and Slater-Condon parameters (CONDON). Some of these methods provide evidence for an asymmetric ground state present in $\mathrm{Bk}^{\mathrm{IV}}$ that does not strictly adhere to Russel-Saunders coupling and Hund's Rule even though it possesses a half-filled $5 f^{7}$ shell. Multiple factors contribute to the asymmetry that include $5 f$ electrons being present in microstates that are not solely spin up, spin-orbit coupling induced mixing of low-lying excited states with the ground state, and covalency in the $\mathrm{Bk}^{\mathrm{IV}}-\mathrm{O}$ bonds that distributes the $5 f$ electrons onto the ligands. These factors are absent or diminished in other $f^{7}$ ions such as $\mathrm{Gd}^{\mathrm{III}}$ or $\mathrm{Cm}^{\mathrm{III}}$.

\section{INTRODUCTION}

Oxidative and reductive processes are governed in part by the ability of an element to attain inherently stable empty-, half-, and fully filled electronic configurations as evidenced by the
Received: May 30, 2017

Published: August 17, 2017 
resilience of $\mathrm{Ti}^{\mathrm{IV}}\left(3 d^{0}\right), \mathrm{Mn}^{\mathrm{II}}\left(3 d^{5}\right)$, and $\mathrm{Zn}^{\mathrm{II}}\left(3 d^{10}\right)$ compounds. This basic principle offers reliable predictive capabilities that are augmented by additional factors such as crystal- and ligand-field stabilization, relativistic effects, and spin-orbit coupling. ${ }^{1}$ Rationalizing redox processes in the f-block is more challenging than in the $d$-block because $f$ orbitals can lie within the radius of core orbitals inhibiting their involvement in both redox reactions and bond formation. ${ }^{2}$ Yet lanthanides still adhere to these aforementioned redox principles with cerium $\left(4 f^{1}\right)$, europium $\left(4 f^{6}\right)$, terbium $\left(4 f^{8}\right)$, and ytterbium $\left(4 f^{13}\right)$ all undergoing redox reactions to yield $\mathrm{Ce}^{\mathrm{IV}}\left(4 f^{0}\right), \mathrm{Eu}^{\mathrm{II}}\left(4 f^{7}\right)$, $\mathrm{Tb}^{\mathrm{IV}}\left(4 f^{7}\right)$, and $\mathrm{Yb}^{\mathrm{II}}\left(4 f^{14}\right)$ compounds, respectively. These descriptions of electronic configuration assume that reduced species adopt $4 f^{n+1}$ configurations. However, recent studies on $\mathrm{Ln}^{\mathrm{II}}$ cyclopentadienyl complexes have revealed that subtle factors influence whether they adopt $4 f^{n+1}$ or $4 f^{n} 5 d^{1}$ configurations. ${ }^{3,4}$ Moreover, the role of $4 f$ orbitals in bonding and their presumed core-like nature is, in fact, subject to debate. ${ }^{5}$ In the last several years, X-ray absorption spectroscopy experiments have revealed a small, but non-negligible, degree of hybridization of $4 f$ orbitals with ligand orbitals occurring in $\left[\mathrm{LnCl}_{6}\right]^{3-}$ and $\mathrm{Ln}_{2} \mathrm{O}_{3}(\mathrm{Ln}=\mathrm{Ce}-\mathrm{Eu})$, and therefore our understanding of bonding in the $f$-block continues to evolve as new spectroscopic techniques and computational developments that account for spin-orbit coupling and relativistic effects are brought to bear on this long-standing discourse. ${ }^{6,7}$

In contrast to lanthanides, early actinides display rich redox chemistry because the $5 f$ orbitals extend beyond the core orbitals and can participate in redox reactions and bonding. The highest possible oxidation state of actinides from actinium through at least neptunium, ${ }^{8-11}$ and perhaps plutonium, ${ }^{12,13}$ simply corresponds to emptying of the $5 f$ orbitals of electrons. In contrast, beginning at americium, attaining oxidation states beyond III+ requires large oxidation potentials and stabilizing ligands, and these heavier actinides are often described as lanthanide-like in terms of their redox chemistry. ${ }^{14}$ However, actinides beyond plutonium still adhere to the basic rules of electronic shell stability and thus $\mathrm{Am}^{\mathrm{II}}\left(5 f^{7}\right)$ compounds, much like $\mathrm{Eu}^{\mathrm{II}}\left(4 f^{7}\right)$, can be prepared, albeit with more difficulty. ${ }^{15}$ The challenge of stabilizing $\mathrm{Am}^{\mathrm{II}}$ provides an illustrative example of differences between the $4 f$ and $5 f$ series. Europium metal is divalent; whereas americium metal is trivalent even though both possess $f^{6}$ configurations in $\mathrm{Eu}^{\mathrm{III}}$ and $\mathrm{Am}^{\mathrm{III}}$ cations. Beginning at californium, the stability of the divalent state in actinides diverges from lanthanides and actually becomes more stable in heavier actinides because electronic repulsion increases less rapidly than shielding effects in actinides when compared to lanthanides, ${ }^{1}$ and thus $\mathrm{No}^{\mathrm{II}}\left(5 f^{14}\right)$ is stable with respect to oxidation in aqueous media while $\mathrm{Yb}^{\mathrm{II}}\left(4 f^{14}\right)$ is not. ${ }^{16}$

The remaining actinide lying adjacent to a $5 f^{7}$ electronic configuration is berkelium $\left(5 f^{8}\right)$. The obvious question is whether berkelium, the $5 f$ analog of terbium, can be oxidized to the IV+ oxidation state that would have a half-filled $5 f$ shell. In fact, the potential for the process ranges from +1.37 to $+1.56 \mathrm{~V}$ and is much lower than that of terbium $\left(E^{\circ}=+2.7 \mathrm{~V}\right)$, and is even slightly lower than the oxidation potential of $\mathrm{Ce}^{\mathrm{III}}$ to $\mathrm{Ce}^{\mathrm{IV}}$ in the same media. ${ }^{17}$ The accessibility of $\mathrm{Bk}^{\mathrm{IV}}$ using readily available oxidants renders the chemical separation of berkelium, as opposed to a much more challenging isotopic separation, extraordinarily useful in isolating berkelium from other actinides. ${ }^{18}$ The rapid $\beta$ decay of ${ }^{249} \mathrm{Bk}$, also provides the only source of high-purity ${ }^{249} \mathrm{Cf}$. The similarity of the cerium and berkelium oxidation potentials offers an opportunity to exploit and extend the well-developed redox chemistry of cerium to berkelium. In fact, it was recently demonstrated that complexation of $\mathrm{Bk}^{\mathrm{III}}$ by a siderophore analog results in spontaneous oxidation to $\mathrm{Bk}^{\mathrm{IV}}$ as often occurs when $\mathrm{Ce}^{\mathrm{III}}$ is bound by strong complexants. ${ }^{19}$ The importance of having a redox analog of berkelium cannot be overstated because the extraordinarily high-specific activity and rarity of ${ }^{249} \mathrm{Bk}$ renders true exploratory chemistry both unsafe and impractical. Comparisons of the chemistry of cerium and berkelium also offers insights into the origins of similarities and differences between the $4 f$ and $5 f$ series. $^{20}$

We recently reported the preparation, structure elucidation, characterization, and electronic structure of $\mathrm{Bk}^{\mathrm{III}}(\mathrm{Hdpa})_{3}$ (dpa $=2,5$-dipicolinate) and $\mathrm{Bk}^{\mathrm{III}}$ borate, $\mathrm{Bk}\left[\mathrm{B}_{6} \mathrm{O}_{8}(\mathrm{OH})_{5}\right] .{ }^{21}$ On the most basic level, these studies demonstrated that single crystal $\mathrm{X}$-ray structures can be obtained from compounds containing short-lived isotopes $\left({ }^{249} \mathrm{Bk}, t_{1 / 2}=320 \mathrm{~d}\right)$, a feat that had remained elusive despite considerable efforts. ${ }^{22}$ The use of new synthetic techniques and instrumentation not available until recently opens up the possibility of new chemistry with quite a few other transient isotopes like ${ }^{227} \mathrm{Ac}\left(t_{1 / 2}=21.772 \mathrm{y}\right),{ }^{23}$ ${ }^{147} \mathrm{Pm}\left(t_{1 / 2}=2.624 \mathrm{y}\right)$, and ${ }^{254} \mathrm{Es}\left(t_{1 / 2}=276 \mathrm{~d}\right)$. However, the syntheses of these $\mathrm{Bk}^{\mathrm{III}}$ compounds does not make use of redox-active reagents and does not answer whether a $\mathrm{Bk}^{\mathrm{IV}}$ compound can be successfully crystallized before nuclear decay destroys the sample. A structure for the aforementioned $\mathrm{Bk}^{\mathrm{IV}}$ siderophore complex was not obtained and a structure for a $\mathrm{Bk}^{\mathrm{IV}}$ compound has yet to be reported. ${ }^{19}$ A compound of this type is of particular importance because it allows one to probe the structure and properties of a $5 f^{7}$ compound where the metal ion is not trivalent. Studies on $f^{7}$ systems other than $\mathrm{Eu}^{\mathrm{II}},{ }^{24} \mathrm{Gd}^{\mathrm{III}},{ }^{25}$ and $\mathrm{Cm}^{\mathrm{III}} 26$ are scant because of the challenges in preparing pure $\mathrm{Tb}^{\mathrm{IV}}$ compounds. ${ }^{27,28}$ In addition, many oddities have been found in the physical properties of actinides when the metal ion is not present in its typical oxidation state as exemplified by $\mathrm{Cm}^{\mathrm{IV}} \mathrm{O}_{2}$ that was anticipated to be nonmagnetic, but instead exhibits Curie-Weiss-type magnetic susceptbility. ${ }^{29,30}$ Herein we report the synthesis, crystal structures, electronic spectroscopy, magnetism, and quantum mechanical calculations of $\mathrm{Bk}\left(\mathrm{IO}_{3}\right)_{3}$ and $\mathrm{Bk}\left(\mathrm{IO}_{3}\right)_{4}$ that are benchmarked against the far simpler $\left[\mathrm{BkCl}_{6}\right]^{n-}(n=2$ or 3$)$ complexes. $\mathrm{Bk}\left(\mathrm{IO}_{3}\right)_{4}$ reveals a number of surprises concerning the electronic structure of late actinide compounds.

\section{EXPERIMENTAL SECTION}

Syntheses. Caution! ${ }^{249} B k\left(t_{1 / 2}=320 d\right.$; specific activity $=1.6 \times 10^{3}$ $\mathrm{Ci} / \mathrm{g})$ undergoes $\beta$-decay to ${ }^{249} \mathrm{Cf}\left(t_{1 / 2}=351 \mathrm{y}\right.$; specific activity $=4.1 \mathrm{Ci} /$ g). The latter isotope represents a significant external hazard owing to abundant $\gamma$-ray emission with energies greater than $>300 \mathrm{keV}$. These energies are sufficient to penetrate through multiple layers of lead bricks. It should also be noted that there is a minor $(0.1 \%) \alpha$-decay branch for ${ }^{249} \mathrm{Bk}$ that yields ${ }^{245} \mathrm{Am}$. Though this branch does not contribute in a meaningful way to hazards, ${ }^{245} \mathrm{Am}$ rapidly $\beta$-decays to ${ }^{245} \mathrm{Cm}$. All studies with transuranium elements were conducted in a Category II nuclear hazard facility. Moveable lead walls, lead bricks, thick lead sheets, respirators, and long lead vests were used to protect researchers. All experimental results were gathered within $24 \mathrm{~h}$ of crystal formation to minimize the effects of radiation damage on the samples.

Hydrogen peroxide $(3 \%), \mathrm{I}_{2} \mathrm{O}_{5}$, and ${ }^{249} \mathrm{BkCl}_{3} \cdot \mathrm{nH}_{2} \mathrm{O}(\mathrm{ORNL})$ were used without further purification. PTFE-lined autoclaves with a $10 \mathrm{~mL}$ internal volume, and Millipore double-distilled water were used in the reaction.

Synthesis of $\mathrm{Bk}\left(\mathrm{IO}_{3}\right)_{3}$ and $\mathrm{Bk}\left(\mathrm{IO}_{3}\right)_{4} \cdot 150 \mu \mathrm{L}$ of $3 \% \mathrm{H}_{2} \mathrm{O}_{2}$ was added to $\mathrm{BkCl}_{3} \cdot n \mathrm{H}_{2} \mathrm{O}$ containing $4.33 \mathrm{mg}$ of ${ }^{249} \mathrm{Bk}$ in a $10 \mathrm{~mL}$ PTFE liner. This results in a color change from a lime-green solution to the 
precipitation of brick-red $\mathrm{Bk}(\mathrm{OH})_{4}$. The faint green radioluminescence is also quenched in this process. The solid was dried by heating for $2 \mathrm{~h}$ at $115{ }^{\circ} \mathrm{C}$ in muffle furnace located inside of a negative-pressure glovebox. After drying, the solid was rinsed with water to remove ${ }^{249} \mathrm{Cf}$. A 9-fold equivalent excess of iodic acid, initially in the form of $\mathrm{I}_{2} \mathrm{O}_{5}$, was dissolved in $250 \mu \mathrm{L}$ of Millipore water and then added to the $\mathrm{Bk}\left(\mathrm{IO}_{3}\right)_{4}$. The liner was sealed within an autoclave. The mixture was heated at $180{ }^{\circ} \mathrm{C}$ for $60 \mathrm{~h}$, then cooled to $25^{\circ} \mathrm{C}$ over a $22 \mathrm{~h}$ duration. The reaction yielded two different types of crystals: large golden blocks of $\mathrm{Bk}\left(\mathrm{IO}_{3}\right)_{3}$ with an approximate truncated, tetragonal bipyramidal habit (ca. $100 \mu \mathrm{m}$ ) in $>99 \%$ yield and approximately five golden columns of $\mathrm{Bk}\left(\mathrm{IO}_{3}\right)_{4}$ (ca. $100 \mu \mathrm{m}$ in length) as shown in Figure S1

Crystallographic Studies. Single crystals of $\mathrm{Bk}\left(\mathrm{IO}_{3}\right)_{3}$ and $\mathrm{Bk}\left(\mathrm{IO}_{3}\right)_{4}$ were adhered to Mitogen mounts with viscous immersion oil and optically aligned on a Bruker D8 Quest X-ray diffractometer using a digital camera. Initial intensity measurements were performed using a I $\mu \mathrm{S}$ X-ray source (Mo $\mathrm{K} \alpha, \lambda=0.71073 \AA$ ) with high-brilliance and high-performance focusing multilayered optics. QUEST software was used for determination of the unit cells and data collection control. The intensities of reflections of a sphere were collected by a combination of multiple sets of exposures (frames). Each set had a different $\varphi$ angle for the crystal and each exposure covered a range of $0.5^{\circ}$ in $\omega$. Both data collections presented in this paper were taken using a set of standard hemispheres. Data sets were collected at room temperature and $100 \mathrm{~K}$. SAINT software was used for data integration including Lorentz and polarization corrections. The structure was solved by direct methods and refined on $\mathrm{F}^{2}$ by full-matrix least-squares techniques using the program suite SHELXTL. ${ }^{31}$ Structure factors for berkelium are not present in the SHELX software and have to be inputted manually. Solutions were checked for missed symmetry using PLATON. ${ }^{32}$ The Crystallographic Information File (CIF) is available from the Cambridge Crystal Structure Database Center: 1537172 $\left[\mathrm{Bk}\left(\mathrm{IO}_{3}\right)_{3}\right]$ and $1537173\left[\mathrm{Bk}\left(\mathrm{IO}_{3}\right)_{4}\right]$. Selected crystallographic data are provided in Table S1. It should be noted that berkelium is not correctly recognized by the checkcif program, and some of the scattering factors for this element are incorrect in the program. This gives rise to a number of A-level alerts that are artifacts of the checkcif program and are not real errors from the actual structure refinements.

UV-Vis-NIR Spectroscopy. Single crystals of each compound were placed on separate quartz slides under Krytox oil. The slide was contained within a Linkam cryostat throughout the measurements. A Craic Technologies microspectrophotometer was used to collect absorption and photoluminescence data.

Magnetic Susceptibility Measurements. Magnetism measurements were performed on polycrystalline sample of $\mathrm{Bk}\left(\mathrm{IO}_{3}\right)_{3}$ using a Quantum Design VSM Magnetic Properties Measurement System under an applied field of $10 \mathrm{kOe}$ for $4 \mathrm{~K}<300 \mathrm{~K}$, and for $0<H<70$ $\mathrm{kOe}$ at $T=4$ and $50 \mathrm{~K}$. The samples were sealed inside two, different, custom-built Teflon capsules. The outermost capsule was also taped closed. In order to extract the intrinsic magnetic behavior of the $\mathrm{Bk}\left(\mathrm{IO}_{3}\right)_{3}$ sample, data sets were collected with the capsule both empty and full, and the background from the sample holder was subtracted from the signal. Lower temperatures could not be achieved because of the self-heating of the sample.

An unexpected outcome from experimental data is that the value of the effective magnetic moment of $\mu_{\text {eff }}=6.8 \mu_{\mathrm{B}}$ per Bk is dramatically reduced from what is expected for $\mathrm{Bk}^{\mathrm{III}}\left(\mu_{\mathrm{eff}}=9.2 \mu_{\mathrm{B}}\right)$, raising the question whether this value is intrinsic or due to an experimental error, e.g., uncertainty in the measured mass of the $\mathrm{Bk}\left(\mathrm{IO}_{3}\right)_{3}$ or self-heating effects that would populate higher $m_{J}$ states. It is interesting to note that for tetravalent berkelium, Hund's rule results in $\mu_{\text {eff }}=7.9 \mu_{\mathrm{B}} / \mathrm{Bk}$, closer to the experimental value. However, given that the iodate ligand network is charge-balanced by $\mathrm{Bk}^{\mathrm{III}}$, this explanation seems unlikely. Assuming the reduced $\mu_{\text {eff }}$ as a result of a systematic experimental error in the determination of the sample mass, we propose the following strategy to analyze the magnetic properties of $\mathrm{Bk}\left(\mathrm{IO}_{3}\right)_{3}$ : we scale the data by a constant and slightly adjust the background subtraction such that the experimental $\mu_{\text {eff }}$ values at $300 \mathrm{~K}$ are close to the simulated value of $9.32 \mu_{\mathrm{B}}$ derived from spectroscopic data by Carnall. ${ }^{19,21,33,34}$
Time-Resolved Emission, Steady-State Emission and Excitation Spectra. Data were collected at room temperature using an Edinburgh FLS980 spectrometer. The sample, between two microscope slide coverslips, was placed at a $45^{\circ}$ angle relative to the excitation source and detector. For excitation and emission spectra, samples were excited using light output from a housed $450 \mathrm{~W}$ Xe lamp passed through a single grating (1, 1,800 $\mathrm{mm}^{-1}, 250 \mathrm{~nm}$ blaze) Czerny-Turner monochromator. Emission from the sample was first passed through a $515 \mathrm{~nm}$ long-pass color filter, then a single grating (l, $1800 \mathrm{~mm}^{-1}, 500 \mathrm{~nm}$ blaze) Czerny-Turner monochromator and detected by a Peltier-cooled Hamamatsu R928 photomultiplier tube. Time-resolved emission were monitored by using the FLS980s timecorrelated single-photon counting capability (1024 channels; $5 \mu \mathrm{s}$ window) with data collection for 10000 counts. Excitation was provided by an Edinburgh EPL-445 ps pulsed diode laser (444.2 nm, $80 \mathrm{ps}$ fwhm) operated at $200 \mathrm{kHz}$.

Density Functional Theory Calculations on $\mathrm{Am}, \mathrm{Cm}, \mathrm{Cf}$, and Bk lodate Complexes. All the structures reported in this study were fully optimized with the Becke's 3-parameter hybrid functional ${ }^{35}$ combined with the nonlocal correlation functional provided by Perdew/Wang (denoted as B3PW91). ${ }^{36}$ To represent the all actinide atoms, a relativistic energy-consistent small-core pseudopotential obtained from the Stuttgart-Köln ECP library was used in combination with its adapted segmented basis set. ${ }^{37-39}$ For the f-in-core calculations in which the berkelium's oxidation state is fixed either to $+\mathrm{III}$ or $+\mathrm{IV}$, the corresponding $5 f$-in-large-core ECP (augmented by a $f$ polarization function, $\alpha=1.0$ ) was used. ${ }^{40}$ Iodine atoms were treated with their respective small core relativistic effective core potential of Stuttgart and their adapted basis sets ${ }^{41,42}$ that were augmented by a set of $\mathrm{d}$ polarization functions $(\alpha=0.55)$ as proposed by Maron et al. ${ }^{43}$ For the oxygen atoms, the $6-31 \mathrm{G}(\mathrm{d}, \mathrm{p})$ basis set was used. ${ }^{44,45}$ In all computations no constraints were imposed on the geometry. All stationary points have been identified as minima (number of imaginary frequencies $N_{\text {imag }}=0$ ). The vibrational modes and the corresponding frequencies are based on a harmonic force field. Enthalpy energies were obtained at $T=298.15 \mathrm{~K}$ within the harmonic approximation. GAUSSIAN 09 program suite was used in all calculations. ${ }^{46,47}$ Natural Bonding Orbital $(\mathrm{NBO})^{48,49}$ analyses were carried out using the associated module in the Gaussian package. Atoms in Molecule $(\mathrm{AIM})^{50}$ analysis was also performed using the Multiwfn code. ${ }^{51}$ Finally, for the 3D representation of the structures the Chemcraft ${ }^{52}$ program was used as well as for the visualization of the molecular orbitals.

Ab-Initio Wave Function Calculations for $\mathrm{Bk}\left(\mathrm{IO}_{3}\right)_{3}, \mathrm{Bk}\left(\mathrm{IO}_{3}\right)_{4}$, $\mathrm{Cf}\left(\mathrm{IO}_{3}\right)_{3}$, and $\left[\mathrm{BkCl}_{6}\right]^{n-}(n=2$ or 3$)$. Relativistic ab initio wave function calculations for $\mathrm{Bk}\left(\mathrm{IO}_{3}\right)_{3}, \mathrm{Bk}\left(\mathrm{IO}_{3}\right)_{4}$, and $\mathrm{Cf}\left(\mathrm{IO}_{3}\right)_{3}$, were carried out with a developer's prerelease 8 version of Molcas. ${ }^{53}$ The second-order Douglas-Kroll-Hess (DKH2) scalar relativistic Hamiltonian $^{54}$ was employed in the calculations without spin-orbit (SO) coupling. The all electron ANO-RCC Gaussian-type orbital (GTO) basis sets from the Molcas library were used for the ligand atoms. The ANO-RCC basis sets were contracted to DZP quality (I = $22 \mathrm{~s} 19 \mathrm{p} 13 \mathrm{~d} 5 \mathrm{f} 3 g / 6 \mathrm{~s} 5 \mathrm{p} 3 \mathrm{~d} 1 \mathrm{f} ; \quad \mathrm{O}=14 \mathrm{~s} 9 \mathrm{p} 4 \mathrm{~d} 3 \mathrm{f} 2 \mathrm{~g} / 3 \mathrm{~s} 2 \mathrm{p} 1 \mathrm{~d})$. For the berkelium and californium centers, we used a relativistic atomic natural orbital basis set from the ANO-DK3 basis library. This basis, as provided in the library, is in a single- $\zeta$ general contraction. In order to provide additional flexibility, for each angular momentum the two most diffuse primitives in the basis were added as individual basis functions, and an additional uncontraced GTO with an exponent of 2/ 5 times the most diffuse exponent in the original ANO-DK3 basis was added, leading to a $36 \mathrm{~s} 27 \mathrm{p} 19 \mathrm{~d} 14 \mathrm{f} / 10 \mathrm{~s} 8 \mathrm{p} 7 \mathrm{~d} 5 \mathrm{f}$ contraction. The computations used state average CASSCF (Complete Active Space Self Consistent Field). ${ }^{55}$ SO coupling was treated by state interactions between the CASSCF wave functions, using the Restricted Active Space State Interaction (RASSI) program. ${ }^{56}$ For brevity, we refer to the scalar relativistic spin-free (SR, i.e., non-SO) and SO CASSCF calculations as SCF-SR and SCF-SO. The influence of dynamic correlation effects were investigated for the $\mathrm{Bk}\left(\mathrm{IO}_{3}\right)_{3}$ complex by using CASPT2 (Complete Active Space Perturbation Theory at second order) ${ }^{57}$ The CASPT2 calculations were performed using the 
multistate approach with a real shift of 0.2 in order to avoid intruder states. The magnetic susceptibilities were calculated according to references 5859 , and 60 as implemented in the RASSI and Single_Aniso modules of Molcas, respectively, and in some cases from magnetic moment matrix elements and the Van Vleck equation. A local modification of Molcas was used to generate electron density natural orbitals (NOs), and the spin magnetizations from the $\mathrm{SO}$ wave functions. ${ }^{61-63}$ Iso-surfaces of the orbitals were created and visualized with the graphical user interface of the Amsterdam Density Functional (ADF) suite. ${ }^{64}$ Additional all-electron scalar relativistic Kohn-Sham (KS) Density Functional Theory (DFT) calculations were carried out with $\mathrm{ADF}$, using the zeroth-order regular approximation (ZORA) Hamiltonian and triple- $\zeta$ doubly polarized (TZ2P) Slater-type orbital basis sets along with the PBE0 hybrid functional. ${ }^{65,66}$

The calculations were performed first using an active space $\operatorname{CAS}(n, 7)$ which corresponds to the formal $n 5 \mathrm{f}$ occupations of the central ions $\mathrm{Bk}^{\mathrm{IV}}(n=7), \mathrm{Bk}^{\mathrm{III}}(n=8)$, and $\mathrm{Cf}^{\mathrm{III}}(n=9)$ in the seven SR 5f orbitals. Another active space $\operatorname{CAS}(n, 12)$ was investigated, which corresponds to $\operatorname{CAS}(n, 7)$ augmented by the five $6 \mathrm{~d}$ orbitals. The results provided in the article are for this larger active space.

For the description of the spin-orbit coupling on the metal site, the mixing of a relatively large number of SF states is required. For the $\mathrm{Bk}\left(\mathrm{IO}_{3}\right)_{4}$ complex, the state-averaged CASSCF and subsequent RASSI calculations were performed for the spin-octet and all sextet (48) states arising from the $\mathrm{Bk}^{\mathrm{IV}}$ ground term. In the case of $\mathrm{Bk}\left(\mathrm{IO}_{3}\right)_{3}$, all septets (7 roots) and quintets (140 roots) arising from the $\mathrm{Bk}^{3 \mathrm{III}}$ ion ground term were calculated. For $\mathrm{Cf}\left(\mathrm{IO}_{3}\right)_{3}$, all sextets (21 roots) and quartets (224 roots) from the $\mathrm{Cf}^{\mathrm{fII}}$ ion ground term were calculated.

For $\left[\mathrm{BkCl}_{6}\right]^{n-}(n=2$ or 3$)$, CASSCF was also performed. Spinorbit coupling was included in a similar fashion as for the iodate compounds but using NEVPT2 ${ }^{67}$ for the dynamic correlation and a different spin-orbit mean field operator. ${ }^{68}$ These calculations were carried out using the ORCA program developed by the Neese and coworkers, ${ }^{69}$ with the scalar relativistic recontracted SARC-TZVPP basis set. $^{70}$ This basis set accurately represents the HF reference wave functions and provides a good description of CASSCF excitation energies and the effect of the SOC operator when compared to basis set limit. The calculations for the chloride complexes also incorporated the scalar DKH2 operator. In regard to the starting CAS-wave function, three active spaces were considered in order to evaluate the inclusion of: (i) the $5 f$-subshell $[\operatorname{CAS}(8,7)$ and $\operatorname{CAS}(7,7)]$, (ii) the $5 f$ and $6 d$ subshells $[\operatorname{CAS}(8,12)$ and $\operatorname{CAS}(7,12)]$, and (iii) the $5 f$ subshell of berkelium $+3 p$ subshell of chlorine atoms $[\operatorname{CAS}(14,10)$ and $\operatorname{CAS}(13,10)]$.

Computational Details of Solid State Calculations. All solidstate calculations were carried out using periodic boundary conditions and the HSE ${ }^{71}$ functional in the Gaussian suite of programs. ${ }^{47} \mathrm{~A}$ modified Stuttgart relativistic small-core (RSC) basis with an effective core potential ${ }^{2}$ (ECP) was used for the actinide atom; diffuse functions with exponents smaller than 0.1 were removed from the default RSC basis in order to make the calculations computationally feasible. ${ }^{73}$ For the iodine and oxygen atoms, a $3-21 \mathrm{G}$ basis was employed. Single point energy calculations were performed on the experimental crystal structures; two unit cells were considered in order to be able to describe magnetic ordering.

\section{RESULTS AND DISCUSSION}

Synthesis. One of the earliest methods for separating Bk ${ }^{\mathrm{III}}$ from $\mathrm{Cf}^{\mathrm{III}}$ was the addition of iodate to solutions containing mixtures of the two ions. ${ }^{74}$ These mixtures rapidly form because ${ }^{249} \mathrm{Bk}$ undergoes $\beta$ decay at a rate of $1.5 \%$ per week to ${ }^{249} \mathrm{Cf}$. Excess iodate oxidizes $\mathrm{Bk}^{\mathrm{III}}$ to $\mathrm{Bk}^{\mathrm{IV}}$ and $\mathrm{Bk}^{\mathrm{IV}}\left(\mathrm{IO}_{3}\right)_{4}$ rapidly precipitates even on microgram scales. ${ }^{74}$ The putative $\mathrm{Bk}\left(\mathrm{IO}_{3}\right)_{4}$ formed in these reactions has never been characterized. It must be noted that radiolytic reactions can significantly alter chemistry from expectations. For example, successful syntheses of ${ }^{242} \mathrm{Pu}\left(t_{1 / 2}=376000 \mathrm{y}\right)$ compounds is often challenging to extend to ${ }^{239} \mathrm{Pu}\left(t_{1 / 2}=24110 \mathrm{y}\right)$ because of the large increase in highly reactive radiolysis products that create deleterious reaction pathways. ${ }^{75}$ One must also keep in mind that nuclear decay processes can be a million times more energetic than any chemical reaction. ${ }^{76}$ Radiolytic processes with ${ }^{249} \mathrm{Bk}$ have the potential of being extreme owing to its halflife of 320 days. The quantity of ${ }^{249} \mathrm{Bk}$ used in this study is undergoing approximately 260 billion decays per second.

In an effort to prepare a crystalline $\mathrm{Bk}^{\mathrm{IV}}$ iodate, $\mathrm{BkCl}_{3} \cdot n \mathrm{H}_{2} \mathrm{O}$ was reacted with $3 \% \mathrm{H}_{2} \mathrm{O}_{2}$. This reaction results in immediate oxidation of radioluminescent, lime-green $\mathrm{Bk}^{\mathrm{III}}$ to $\mathrm{Bk}^{\mathrm{IV}}$ and precipitation of garnet-colored, $\mathrm{Bk}(\mathrm{OH})_{4}$. This reaction leaves the ${ }^{249} \mathrm{Cf}$ daughter in solution and has been used to prepare spectroscopic-grade samples of ${ }^{249} \mathrm{Bk}$ that are temporarily free from optical features from the ingrowth of californium. ${ }^{77} \mathrm{We}$ observed that replicating this reaction was best done with the addition of a few microliters of $0.01 \mathrm{M} \mathrm{NH}_{4} \mathrm{OH}$ to increase the $\mathrm{pH}$. The mother liquor was removed and the $\mathrm{Bk}(\mathrm{OH})_{4}$ briefly dried and then washed multiple times with Millipore water to remove any residual californium. A 9-fold excess of iodic acid was then added to the $\mathrm{Bk}(\mathrm{OH})_{4}$ along with $250 \mu \mathrm{L}$ of water, and the reaction mixture was then heated at $180{ }^{\circ} \mathrm{C}$ for $60 \mathrm{~h}$ followed by slow cooling to room temperature. The product consisted of large $(>100 \mu \mathrm{m})$, golden blocks with an approximate truncated, tetragonal bipyramidal habit along with trace amounts (exactly five microcrystals were observed) of acicular crystals that were also golden in color (see ESI Figure S1). Both types of crystals began to shed their outer surface with $48 \mathrm{~h}$ and subsequently underwent Coulombic explosions in less than 2 weeks owing to building up of positive charge within the crystals. Analysis of the two different crystal types demonstrated that the dominant product of this reaction is $\mathrm{Bk}\left(\mathrm{IO}_{3}\right)_{3}$ and that the trace product is $\mathrm{Bk}\left(\mathrm{IO}_{3}\right)_{4}$. This is a clear example of radiolysis influencing a reaction by creating a highly reducing environment, which is expected for an intense $\beta$ emitter. The fortuitous isolation of any $\mathrm{Bk}\left(\mathrm{IO}_{3}\right)_{4}$ can be ascribed to its low solubility and rapid crystallization from the initial solution before reduction of $\mathrm{Bk}^{\mathrm{IV}}$ to $\mathrm{Bk}^{\mathrm{III}}$ could occur. This probably also explains the small size of the crystals. Reduction of $\mathrm{Bk}^{\mathrm{IV}}$ to $\mathrm{Bk}^{\mathrm{III}}$ can also be caused by the thermal decomposition of iodate into $\mathrm{I}_{2}$ and periodate. Iodine is a known reductant of high-valent actinides to lower oxidation states and will reduce $\mathrm{Bk}^{\mathrm{IV}}$ to $\mathrm{Bk}$

Structure Determinations. Single crystal X-ray diffraction experiments on $\mathrm{Bk}\left(\mathrm{IO}_{3}\right)_{3}$ reveal that it adopts the $\mathrm{Bi}\left(\mathrm{IO}_{3}\right)_{3}$ structure type, which is paralleled by both $\mathrm{Am}^{\mathrm{III}}$ and $\mathrm{Cf}^{\mathrm{III}} .78,79$ $\mathrm{Eu}^{\mathrm{III}}$ or $\mathrm{Gd}^{\mathrm{III}}$ should have the closest ionic radii with $\mathrm{Bk}^{\mathrm{III}}, 80$ and can also adopt this structure. ${ }^{81} \mathrm{Bk}\left(\mathrm{IO}_{3}\right)_{3}$ forms a layered structure consisting of $\mathrm{Bk}^{\mathrm{III}}$ ions bound by seven iodate anions. Two of these are chelating and five are monodentate resulting in a nine-coordinate, tricapped, trigonal prismatic environment around the berkelium site as shown in Figure 1a. Bridging between berkelium centers by the iodate anions creates the layers that are depicted in Figure 1b. Using the crystallographic data from $f$-block iodates, the ionic radius of $\mathrm{Bk}^{\mathrm{III}}$ was calculated by using the slopes of unit cell volume $(V)$ vs $r^{3}$ ( $r=$ ionic radius) as performed by Shannon. ${ }^{82}$ This method yields an ionic radius for nine-coordinate $\mathrm{Bk}^{\mathrm{III}}$ to be $1.112(3) \AA$. This radius lies between $\mathrm{Eu}^{\mathrm{III}}(1.12 \AA)$ and $\mathrm{Gd}^{\mathrm{III}},(1.107 \AA) .{ }^{82} \mathrm{Cm}^{\mathrm{III}}$ cannot be directly compared to this system because it adopts a different structure type that contains eight-coordinate $\mathrm{Cm}^{\mathrm{III}} .{ }^{83}$ However, this ionic radius confirms a slightly larger than expected contraction from that calculated for $\mathrm{Am}^{\mathrm{III}}$, which has a ionic radius of $1.162(3) \AA .{ }^{84}$ The expected reduction is $\sim 0.03$ 

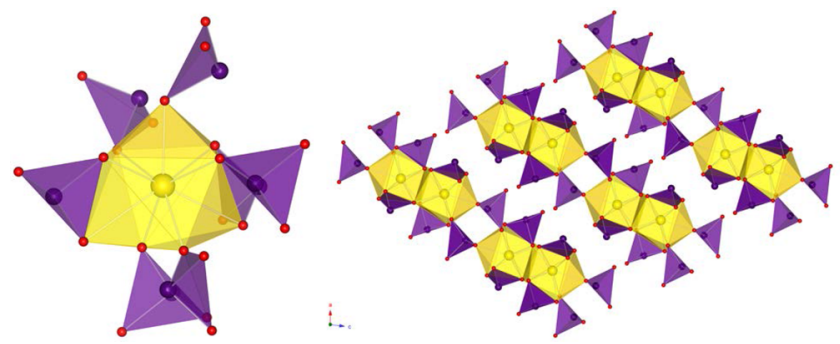

Figure 1. (a) Nine-coordinate, distorted tricapped trigonal prismatic coordination of $\mathrm{Bk}^{\mathrm{III}}$ in $\mathrm{Bk}\left(\mathrm{IO}_{3}\right)_{3}$. (b) View of part of $\mathrm{Bk}\left(\mathrm{IO}_{3}\right)_{3}$ along the $b$ axis showing stacking of the layers.

$\AA$, but the measurements yield $0.050(3) \AA$. Similar values were observed in $\mathrm{Bk}(\mathrm{Hdpa})_{3}$ and $\mathrm{Bk}\left[\mathrm{B}_{6} \mathrm{O}_{8}(\mathrm{OH})_{5}\right]$ as well as in the $\mathrm{Cf}^{\mathrm{III}}$ analogs. ${ }^{21,85,86}$ Recent studies on berkelium and californium siderophore complexes also show this deviation from expectations in postcurium, actinide-ligand interactions. Table S2 provides a complete list of the $\mathrm{An}-\mathrm{O}(\mathrm{An}=\mathrm{Am}, \mathrm{Bk}$, $\mathrm{Cf})$ bond distances found for $\mathrm{An}\left(\mathrm{IO}_{3}\right)_{3}$ compounds.

In contrast to $\mathrm{M}\left(\mathrm{IO}_{3}\right)_{3}(\mathrm{M}=\mathrm{Ln}$ or $\mathrm{An})$ compounds, the $\mathrm{M}\left(\mathrm{IO}_{3}\right)_{4}$ family do not exhibit polymorphism with the same metal ion. Although hydrates and compositionally more complex $\mathrm{Ce}^{\mathrm{IV}}$ and $\mathrm{Np}^{\mathrm{IV}}$ iodates have been isolated and characterized. ${ }^{87,88}$ In fact, there are only two known structure types for compounds with the formula $\mathrm{M}\left(\mathrm{IO}_{3}\right)_{4} \cdot{ }^{89,90}$ The first of these is the $\mathrm{Ce}\left(\mathrm{IO}_{3}\right)_{4}$-type that also occurs with $\mathrm{Np}^{\mathrm{IV}}$ and $\mathrm{Pu}^{\mathrm{IV}}{ }^{88} \mathrm{Zr}\left(\mathrm{IO}_{3}\right)_{4}$ adopts a different structure type that ostensibly reflects the much smaller ionic radius of $\mathrm{Zr}^{\mathrm{IV}}(0.84$ $\AA$ ) versus the tetravalent $f$-elements $\left(0.93 \AA\right.$ for $\left.\mathrm{Bk}^{\mathrm{IV}}\right) .{ }^{89,90}$ The structure determination of $\mathrm{Zr}\left(\mathrm{IO}_{3}\right)_{4}$ was originally pursued because it appeared to deviate from Pauling's Rules for determining the coordination environment of metal ions in solids. ${ }^{89}$ The violation was confirmed, and $\mathrm{Zr}\left(\mathrm{IO}_{3}\right)_{4}$ contains an almost ideal Archimedean antiprism, now called a square antiprism in modern literature. ${ }^{89-91}$ The expectation would be that even though $\mathrm{Bk}^{\mathrm{IV}}$ is smaller than $\mathrm{Pu}^{\mathrm{IV}}$ by at least $0.03 \AA$ that it should still adopt the $\mathrm{Ce}\left(\mathrm{IO}_{3}\right)_{4}$-structure type. However, $\mathrm{Bk}\left(\mathrm{IO}_{3}\right)_{4}$ defies predictions based on ionic radii and is isomorphous with $\mathrm{Zr}\left(\mathrm{IO}_{3}\right)_{4}$ as shown in Figure 2a. The $\mathrm{Ce}\left(\mathrm{IO}_{3}\right)_{4^{-}}$and $\mathrm{Zr}\left(\mathrm{IO}_{3}\right)_{4}$-structure types are grossly different. The former contains one-dimensional chains composed of eight-coordinate metal ions that are bridged by iodate as depicted in Figure 2b; whereas the latter is a layered structure.

In addition to changes in the dimensionality of the structure types, the local coordination environment of the $\mathrm{M}^{\mathrm{IV}}$ centers

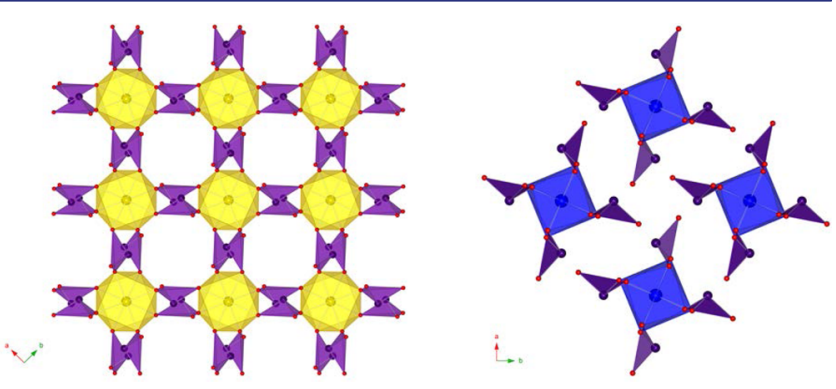

Figure 2. (a) Depiction of part of a layer parallel to the $[a b]$ plane in $\mathrm{Bk}^{\mathrm{IV}}\left(\mathrm{IO}_{3}\right)_{4}$ showing nearly ideal, square antiprismatic coordination of $\mathrm{Bk}^{\mathrm{IV}}$ by iodate anions. (b) Illustration of the one-dimensional chains in the $\mathrm{M}\left(\mathrm{IO}_{3}\right)_{4}(\mathrm{M}=\mathrm{Ce}, \mathrm{Np}, \mathrm{Pu})$ structure type viewed along the chain (c-axis). differs as well. In contrast to $\mathrm{Zr}\left(\mathrm{IO}_{3}\right)_{4}$, the $\mathrm{Ce}\left(\mathrm{IO}_{3}\right)_{4}$-structure type contains a $\mathrm{MO}_{8}$ unit that conforms much closer to a trigonal dodecahedron $\left(D_{2 d}\right)$ than a square antiprism $\left(D_{4 d}\right){ }^{92,93}$ Whether or not these distortions between different geometries of eight-coordinate metals reflect changing roles of metal orbitals in bonding has been debated for decades. ${ }^{91}$ However, there is computational evidence that supports this argument. $^{94,95}$ Extensive experimental and computational efforts are needed to confirm that different structures are actually manifestations of the divergent chemistry of different elements rather than subtle factors that influence crystallization. Quantum mechanical calculations provide evidence for significant covalent contributions to $\mathrm{Bk}^{\mathrm{IV}}-\mathrm{O}$ bonds (vide infra).

As expected, the $\mathrm{Bk}^{\mathrm{IV}}-\mathrm{O}$ bonds appear to be longer than those observed in $\mathrm{Zr}\left(\mathrm{IO}_{3}\right)_{4}$ and average 2.280 (3) versus $2.21(2) \AA{ }^{89,90}$ Although, there is minor overlap of the distances at the $3 \sigma$ limit owing to the lower precision of the $\mathrm{Zr}\left(\mathrm{IO}_{3}\right)_{4}$ structure determination. However, this distance is shorter than that measured in $\mathrm{Pu}\left(\mathrm{IO}_{3}\right)_{4}$ by $0.053(5) \AA$ and is outside of the range of what would be predicted for a monotonic actinide contraction. ${ }^{95-100}$ Though this observation seems to only reiterate previous arguments made for $\mathrm{Bk}^{\mathrm{III}}$ and $\mathrm{Cf}^{\mathrm{III}}$ compounds, the bond-valence sum for the berkelium site in $\mathrm{Bk}\left(\mathrm{IO}_{3}\right)_{4}$ is $4.40 .^{101}$ Bond-valence calculations are not particularly precise, but this deviation from the expected value of 4 is outside of the normal variance in bond-valence sums for metal ions with single oxidation states. Extrapolation from this single value provides the outlandish suggestion that the berkelium site is exhibiting partial $\mathrm{Bk}^{\mathrm{V}}$ character. The bondvalence parameter cannot have been derived from experimental data because no $\mathrm{Bk}^{\mathrm{IV}}$ single crystal structures have ever been reported. Therefore, the $\mathrm{Bk}^{\mathrm{IV}}$ bond-valence parameter must have been calculated by extrapolating from lighter actinides. We have demonstrated here that this extrapolation misses the break after $\mathrm{Cm}^{\mathrm{III}}$. Curiously, density-functional theory calculations corroborate the higher than expected BVS, and evolution of oxidation states in $\mathrm{Bk}\left(\mathrm{IO}_{3}\right)_{4}$ is supported by photoluminescence measurements (vide infra). The overly contracted $\mathrm{Bk}^{\mathrm{IV}}-$ $\mathrm{O}$ bonds may not be the only explanation for $\mathrm{Bk}\left(\mathrm{IO}_{3}\right)_{4}$ adopting the $\mathrm{Zr}\left(\mathrm{IO}_{3}\right)_{4}$ structure. It was noted during the investigation of the $\mathrm{Zr}\left(\mathrm{IO}_{3}\right)_{4}$ structure that it contains abnormally large voids. ${ }^{89,90}$ Recalling that the structure is layered, these two factors allow for swelling by larger metal cations without inducing large amounts of strain on the lattice. The same can also be said of the $\mathrm{Ce}\left(\mathrm{IO}_{3}\right)_{4}$-structure type because it is one-dimensional.

Electronic Spectroscopy. Absorption, excitation, and photoluminescence spectra of $\mathrm{Bk}\left(\mathrm{IO}_{3}\right)_{3}$ and $\mathrm{Bk}\left(\mathrm{IO}_{3}\right)_{4}$ were collected from single crystals of each compound. The spectra were recollected from the same crystals over the course of 2 weeks to monitor spectral evolution that was expected to occur owing to both radiation damage induced by the high specific activity of ${ }^{249} \mathrm{Bk}$ and the ingrowth of ${ }^{249} \mathrm{Cf}$. A broadband feature is observed for $\mathrm{Bk}\left(\mathrm{IO}_{3}\right)_{3}$ that begins in the high-energy region of visible spectrum and extends into the UV as shown in Figure 3. This feature has been assigned as a Laporte-allowed, $5 f \rightarrow 6 d$ transition that is consistent with both its intensity and lack of fine features that become evident at lower energies. ${ }^{19,21,33,34}$ This band is followed by a series of much weaker, sharp lines that have been assigned in several compounds including $\mathrm{Bk}(\mathrm{Hdpa})_{3}$ and $\mathrm{Bk}\left[\mathrm{B}_{6} \mathrm{O}_{8}(\mathrm{OH})_{5}\right]$ to $5 f \rightarrow 5 f$ transitions. ${ }^{21,33,34}$ $\mathrm{Bk}\left(\mathrm{IO}_{3}\right)_{3}$ is expected to luminesce in the red region of the visible spectrum and variable-temperature, photoluminescence 

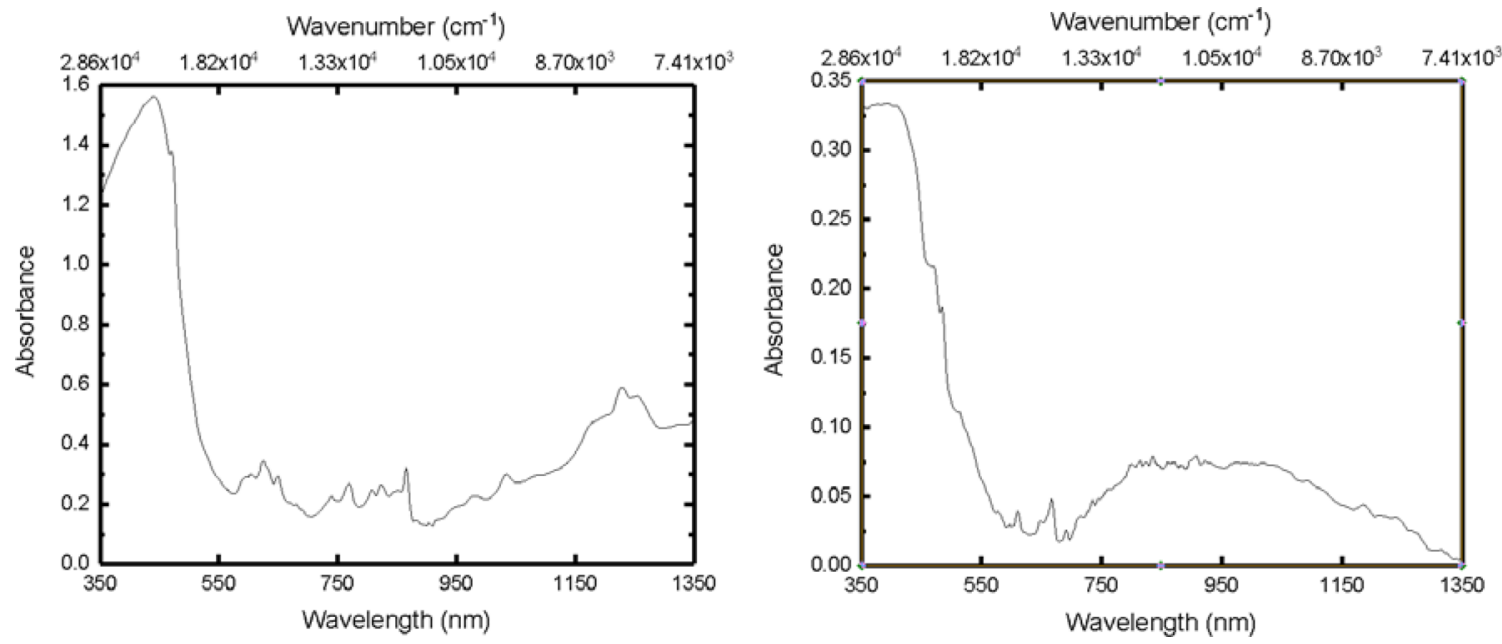

Figure 3. UV-vis-NIR absorption spectra of $\mathrm{Bk}\left(\mathrm{IO}_{3}\right)_{3}$ (left) and $\mathrm{Bk}\left(\mathrm{IO}_{3}\right)_{4}$ (right) collected within $24 \mathrm{~h}$ of crystal formation.

spectra reveal luminescence at $670 \mathrm{~nm}(J=6)$ (see Figures 4 and 5). ${ }^{19,33,34}$ The long lifetime of the excited state of $878 \mathrm{~ns}$ is

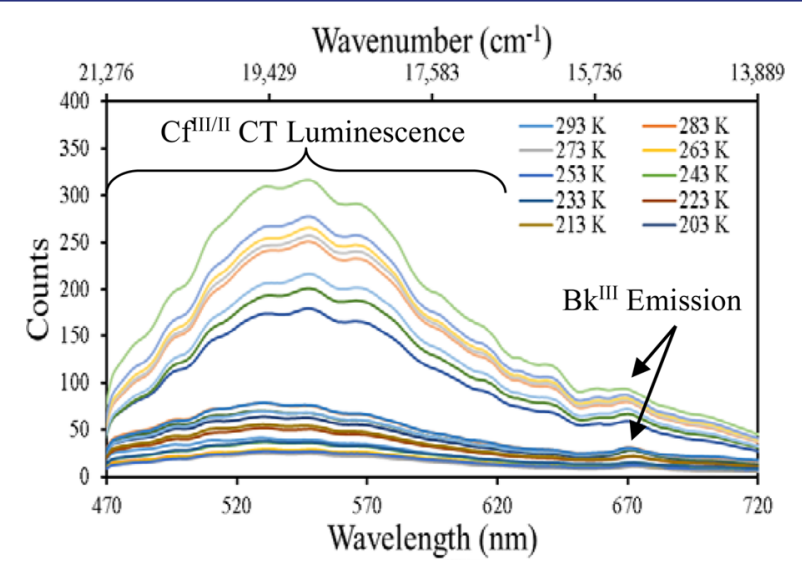

Figure 4. Temperature-dependent photoluminescence spectrum of $\mathrm{Bk}\left(\mathrm{IO}_{3}\right)_{3}\left(\lambda_{\mathrm{Ex}}=420 \mathrm{~nm}\right)$.

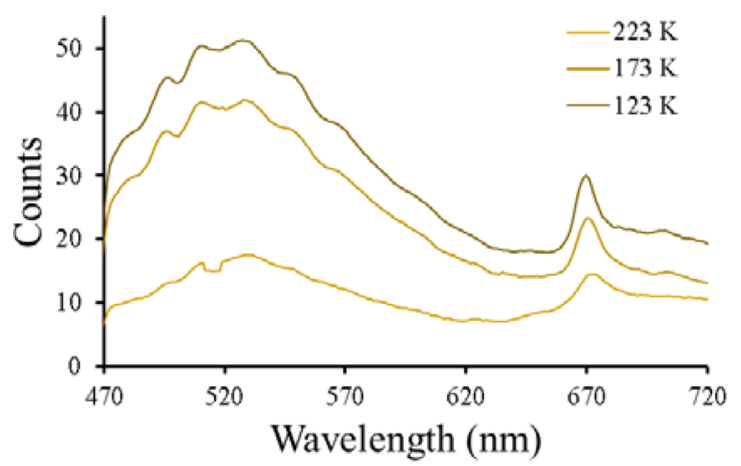

Figure 5. Temperature-dependent photoluminescence spectrum of $\mathrm{Bk}\left(\mathrm{IO}_{3}\right)_{4}\left(\lambda_{\mathrm{Ex}}=420 \mathrm{~nm}\right)$.

consistent with $5 f 6 d$ mixing as expected for berkelium in the absence of inner-sphere water molecules. ${ }^{19,33,34}$ At the beginning of these experiments, the sample contained $<5 \%$ ${ }^{249} \mathrm{Cf}$. It likely possessed even lower amounts of californium given the selective precipitation of $\mathrm{Bk}(\mathrm{OH})_{4}$ used in its synthesis. However, the broadband luminescence from the ingrowth of $\mathrm{Cf}^{\mathrm{III}}$ is evident (see Figure 4) from the outset because this transition is an allowed ligand-to-metal chargetransfer band whereas the $5 f \rightarrow 5 f$ transitions are forbidden. ${ }^{1,102}$

The optical features of $\mathrm{Bk}\left(\mathrm{IO}_{3}\right)_{4}$ are more complex and evolve significantly with time even if the ingrowth of ${ }^{249} \mathrm{Cf}$ is discounted. First, it must be noted that $\mathrm{Bk}^{\mathrm{IV}}$ is isoelectronic with $\mathrm{Cm}^{\mathrm{III}}$ and both are $5 f^{7}$. Spin-orbit coupling is larger in $\mathrm{Bk}^{\mathrm{IV}}$ than it is in $\mathrm{Cm}^{\mathrm{III}}$, and there are additional energy levels present in $\mathrm{Bk}^{\mathrm{IV}}$ that allow for nonradiative relaxation. ${ }^{19,21,33,34}$ The high-energy region of the absorption spectrum is quite similar to that of $\mathrm{Cm}^{\mathrm{III}}$ with a series of sharp features centered near $450 \mathrm{~nm} .{ }^{18}$ Luminescence should be observed for $\mathrm{Bk}^{\mathrm{IV}}$ near $600 \mathrm{~nm} .^{19,33,34}$ If this feature is present, it is masked by the tail of the broadband luminescence from $\mathrm{Cf}^{\mathrm{III}}$. However, based on photoluminescence studies from the ingrowth of ${ }^{245} \mathrm{Cm}$ into ${ }^{249} \mathrm{Cf}$ samples via $\alpha$ decay, the feature appears to be absent. $^{21,85,86}$ Immediately evident is luminescence at $670 \mathrm{~nm}$ consistent with the presence of $\mathrm{Bk}^{\mathrm{III}}$ in the sample (Figures 4 and 5). ${ }^{19,21,33,34,102,103}$ Furthermore, a broad absorption feature is initially present that spans from $\sim 640$ to $1300 \mathrm{~nm}$ as shown in Figure 3. Over the course of several days, this broad feature as well as the luminescence at $670 \mathrm{~nm}$ becomes less intense and disappears. These data are consistent with a transient, mixedvalent state with the broadband feature in the absorption spectra at low energies denoting an intervalence charge-transfer band as has been observed in $\mathrm{Ce} \mathrm{e}^{\mathrm{III} / \mathrm{IV}}$ iodates. ${ }^{104}$ The simplest explanation is that at the time the crystals form that a mixture of $\mathrm{Bk}^{\mathrm{III}}$ and $\mathrm{Bk}^{\mathrm{IV}}$ is present and that a small amount of $\mathrm{Bk}^{\mathrm{III}}$ is incorporated in the $\mathrm{Bk}\left(\mathrm{IO}_{3}\right)_{4}$ crystals. However, the $\mathrm{Bk}\left(\mathrm{IO}_{3}\right)_{4}$ lattice must stabilize $\mathrm{Bk}^{\mathrm{IV}}$ and the rapid $\beta$ decay causes the crystals to become gradually more positive. This process leads to oxidation of any residual $\mathrm{Bk}^{\mathrm{III}}$ to $\mathrm{Bk}^{\mathrm{IV}}$. Though it is not possible to quantify the amount of $\mathrm{Bk}^{\mathrm{III}}$ in the crystal, it must be quite small because lengthening of the $\mathrm{Bk}^{\mathrm{IV}}-\mathrm{O}$ bond distances in the crystal structure of $\mathrm{Bk}\left(\mathrm{IO}_{3}\right)_{4}$ is not noted. If a significant percentage of $\mathrm{Bk}^{\mathrm{III}}$ was present in $\mathrm{Bk}\left(\mathrm{IO}_{3}\right)_{4}$ the $\mathrm{Bk}-\mathrm{O}$ bond lengths would be an average of $\mathrm{Bk}^{\mathrm{III}}-\mathrm{O}$ and $\mathrm{Bk}^{\mathrm{IV}}$.

The $\lambda_{\max }$ for the broadband luminescence from the ingrowth of ${ }^{249} \mathrm{Cf}$ into $\mathrm{Bk}\left(\mathrm{IO}_{3}\right)_{4}$ is shifted to higher energies by approximately $20 \mathrm{~nm}$ from that observed in $\mathrm{Bk}\left(\mathrm{IO}_{3}\right)_{3}$. This shift can be attribute to the differences in the host lattices. The broadband feature has been assigned to ligand-to-metal charge transfer, i.e., the formal reduction of $\mathrm{Cf}^{\mathrm{III}}$ to $\mathrm{Cf}^{\mathrm{II}}$. Therefore, 
charge-transfer from iodate to $\mathrm{Cf}^{\mathrm{III}}$ should occur at higher energies in $\mathrm{Bk}^{\mathrm{IV}}$ iodate than in $\mathrm{Bk}^{\mathrm{III}}$ iodate because of inductive effects.

Magnetic Susceptibility of $\mathrm{Bk}\left(\mathrm{IO}_{3}\right)_{3}$. To improve our understanding of the $f$-electron state of the berkelium ions, measurements of the molar magnetic susceptibility $(\chi=M / H)$ of $\mathrm{Bk}\left(\mathrm{IO}_{3}\right)_{3}$ were performed in a magnetic field of $H=0.1 \mathrm{~T}$ for temperatures $6<T<300 \mathrm{~K}$ (Figure 6a).

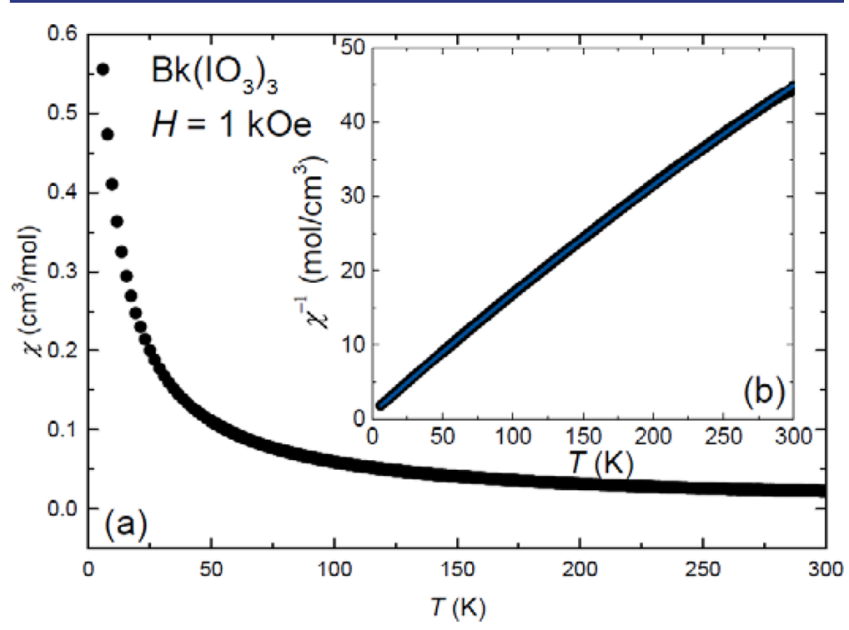

Figure 6. (a) Magnetic susceptibility $\chi(T)=M(T) / H$ for $H=1 \mathrm{kOe}$ vs temperature $T$ for a mosaic of randomly aligned crystallites of $\mathrm{Bk}\left(\mathrm{IO}_{3}\right)_{3}$. The data presented here have had the Teflon sample holder background signal subtracted to reveal the intrinsic behavior of $\mathrm{Bk}\left(\mathrm{IO}_{3}\right)_{3}$. (b) $\chi^{-1}(\mathrm{~T})$ for $\mathrm{Bk}\left(\mathrm{IO}_{3}\right)_{3}$, where the solid line is a CurieWeiss fit to the data, as described in the text.

To reproduce these data, the $\mathrm{Bk}^{3+}$ coordination environment in $\mathrm{Bk}\left(\mathrm{IO}_{3}\right)_{3}$ was approximated as nine-coordinate, tricapped trigonal prismatic with $C_{3 v}$ site symmetry. An additional interesting feature in the structure of $\mathrm{Bk}\left(\mathrm{IO}_{3}\right)_{3}$ is the presence of edge-sharing interactions between the $\left[\mathrm{BkO}_{9}\right]$ polyhedra leading to one-dimensional chains in the structure, shown in Figure $1 \mathrm{~b}$, with alternating short-long $\mathrm{Bk} \cdots \mathrm{Bk}$ distances of 4.195 and $4.499 \AA$. These two different distances are within the expectation range for significant magnetic coupling phenomena. Therefore, all coupling interactions between neighboring berkelium ions were accounted for via the phenomenological mean field model,

$$
\chi_{\mathrm{m}}^{-1}=\chi_{\mathrm{m}}^{-1}\left(\varsigma, F^{k}, B_{\mathrm{q}}^{k}\right)-\lambda_{\mathrm{mf}}
$$

where $\chi_{\mathrm{m}}$ denotes the molar magnetic susceptibility per $\mathrm{Bk}^{\mathrm{III}}$ ion and $\lambda_{\mathrm{mf}}$ the molecular field parameter. The title compound offers a unique opportunity to investigate the magnetism of the $\mathrm{Bk}^{\mathrm{III}}$ cations with CONDON in a low-dimensional system. It would be of fundamental interest to search for the possibility of magnetic ordering or magnetic transitions in $\mathrm{Bk}\left(\mathrm{IO}_{3}\right)_{3}$ and to study the role of the $5 f$ electrons in the resultant magnetic behavior.

The susceptibility data were fitted to a "full-model" Hamiltonian, ${ }^{105-107}$ where the relevant spin-orbit coupling parameter $\left(\zeta=3210 \mathrm{~cm}^{-1}\right)$ and Slater-Condon parameters $\left(F^{2}\right.$ $=57697 \mathrm{~cm}^{-1}, F^{4}=45969 \mathrm{~cm}^{-1}$, and $\left.F^{6}=32876 \mathrm{~cm}^{-1}\right)$ were chosen on the basis of the optical spectra of $\mathrm{BkCl}_{3}$ and used as constants. ${ }^{101}$ In order to restrict the number of independent ligand-field parameters, a least-squares fit of the magnetic data for $\mathrm{Bk}\left(\mathrm{IO}_{3}\right)_{3}$ requires assuming an idealized $C_{3 v}$ symmetry of the $\mathrm{BkO}_{9}$ environment. Here, the ligand-field operator with reference to the 3-fold rotation axis for the angular part of the wave function reads ${ }^{108}$

$$
\begin{aligned}
H_{\mathrm{lf}}^{\mathrm{C} 3 \mathrm{v}}= & \sum_{i=1}^{N} B_{0}^{2} C_{0}^{2}(i)+\sum_{i=1}^{N} B_{0}^{4} C_{0}^{4}(i) \\
& +\sum_{i=1}^{N} B_{3}^{4}\left(C_{-3}^{4}(i)+C_{3}^{4}(i)\right)+\sum_{i=1}^{N} B_{0}^{6} C_{0}^{6}(i) \\
& +\sum_{i=1}^{N} B_{3}^{6}\left(C_{-3}^{6}(i)+C_{3}^{6}(i)\right) \\
& +\sum_{i=1}^{N} B_{6}^{6}\left(C_{-6}^{6}(i)+C_{6}^{6}(i)\right)
\end{aligned}
$$

Initial sets of most ligand field $\left(B_{q}^{k} \text {; Wybourne notation }\right)^{109}$ parameters were again adopted from spectroscopically determined energy levels for $\mathrm{BkCl}_{3}$, whereas the $\mathrm{Bk}^{\mathrm{III}}$ site symmetry reduction from $D_{3 h}\left(\mathrm{BkCl}_{3}\right)$ to $C_{3 v}$ mandates two further additional ligand-field parameters $\left(B_{3}^{4}\right.$ and $\left.B_{3}^{6}\right)$. The signs and ratio of the $B_{3}^{k} / B_{0}^{k}$ (with $k=4$ and $6 ; B_{3}^{4} / B_{0}^{4}=$ $-\sqrt{10 / 7}$ and $\left.B_{3}^{6} / B_{0}^{6}=\sqrt{210 / 24}\right)$ values are assigned from point charge electrostatic model calculations for a regular tricapped trigonal prism and are fixed throughout the fitting procedure. This results are in good agreement with the experimental data $(S Q=0.5 \%)$ yielding a ligand field characterized by $B_{0}^{2}=100 \mathrm{~cm}^{-1}, B_{0}^{4}=-700 \mathrm{~cm}^{-1}, B_{3}^{4}=827$ $\mathrm{cm}^{-1}, B_{0}^{6}=-1320 \mathrm{~cm}^{-1}, B_{3}^{6}=-790 \mathrm{~cm}^{-1}, B_{6}^{6}=810 \mathrm{~cm}^{-1}$, and $\lambda_{\mathrm{mf}}=-6.52 \times 10^{4} \mathrm{~mol} \mathrm{~m}^{-3}$. Importantly, the composition of the ground term $\left({ }^{7} F(70 \%) ;{ }^{5} G(23 \%)\right)$ is line with spectroscopic data. The total splitting of the ${ }^{7} F_{6}$ ground state into $m_{J}$ substates amounts to $207.7 \mathrm{~cm}^{-1}$, with an energy gap of $7.2 \mathrm{~cm}^{-1}$ between ground state and first excited state as shown in Figure 7. The observed temperature dependence of $\mu_{\text {eff }}$ below $50 \mathrm{~K}$ is ascribed to the composition of ground state (mixture of $m_{J}=0(13 \%)$ of $m_{J}= \pm 3(9 \%)$ and $72 \% m_{J}= \pm 6$ states). The calculations also support that the $\mathrm{IO}_{3}{ }^{-}$bridges mediate antiferromagnetic exchange (negative $\lambda_{\mathrm{mf}}$ value) over

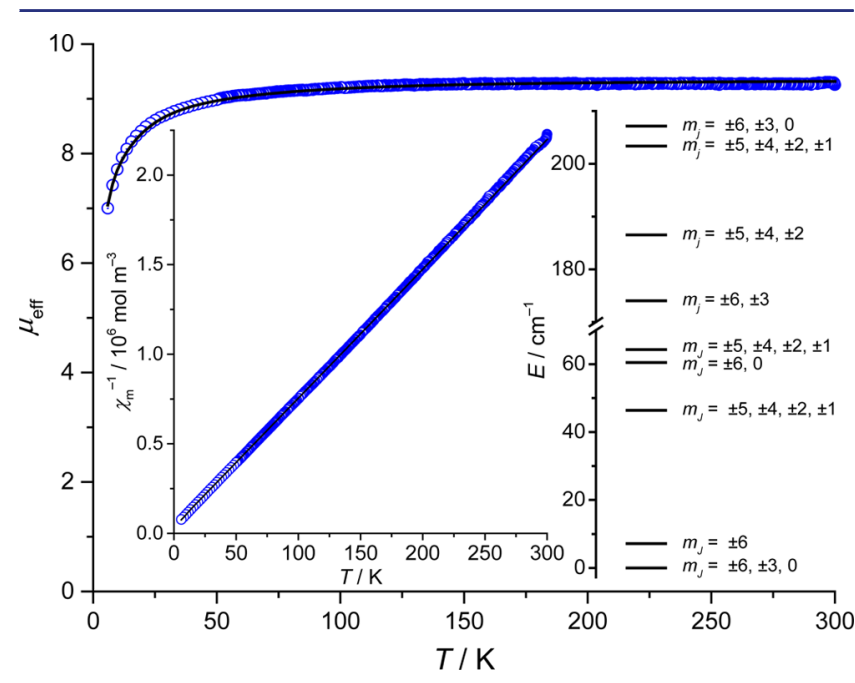

Figure 7. Magnetic moment $\mu_{\text {eff }}$ vs $T$ and inverse susceptibility vs $T$ (inset) of polycrystalline samples of $\mathrm{Bk}\left(\mathrm{IO}_{3}\right)_{3}$ at $0.1 \mathrm{~T}$. Open circles, experimental data; solid black lines, least-squares fits to "full model" Hamiltonian. The energy level diagrams display the splitting of the lowest multiplet states and their composition. 
nearest-neighbor distances and are in line with the bandstructure calculations that show antiferromagnetic coupling between the $\mathrm{Bk}^{\mathrm{III}}$ sites (vide infra). All these results are line with the magnetic moment of the ground state $\left|\mu_{z}\right|=4.6 \mu_{\mathrm{B}}$ that is reduced nearly by $50 \%$ from the "free ion value" of $9.32 \mu_{\mathrm{B}}$, and the occupation of the orbitals of the ground state shows that all electrons are distributed over all $m_{l}$ values and not concentrated in states with particular $m_{l}$ values as shown in Figure 8.

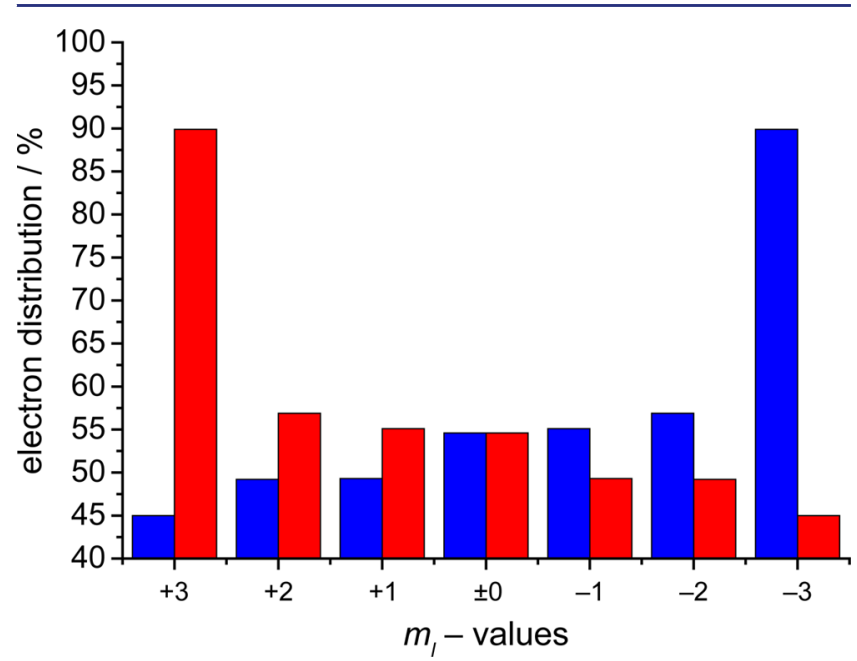

Figure 8. Electron distribution or occupation of the $m_{l}$ states for the ground state $\mathrm{Bk}^{3+}$ (spin up and spin down component).

These results lead to the following important point for $a b$ initio methods in predicting the electronic structure of the ground term in that they have to include all effects acting on the magnetic center simultaneously. Otherwise, considerable information about the ground state, which determinates the magnetic properties, is lost. In the case of DFT calculations, multiconfigurational wave functions cannot be taken into account, thus mixed states cannot be considered although such reflect the actual ground state of $\mathrm{Bk}^{\mathrm{III}}$.

Theoretical Estimation of Magnetic Susceptibility of $\mathrm{Bk}\left(\mathrm{IO}_{3}\right)_{4}$. Simulation of the experimental spectroscopic data of $\mathrm{CmCl}_{3} / \mathrm{Cm}^{3+}: \mathrm{LaCl}_{3}$ and $\mathrm{Bk}^{4+}: \mathrm{CeF}_{4}$ allow for the evaluation the magnetic susceptibility of $\mathrm{Bk}\left(\mathrm{IO}_{3}\right)_{4}{ }^{71,101,110}$ This is performed by fitting the experimentally determined crystal-field splitting to obtain the full set of If parameters (see Table S3) and shows a good agreement between simulation and experimental data ( $S Q$ $<0.8 \%$ ). In Figure 9 (inset right) the exp. (black lines) and clac. (purple lines) ligand field splitting patterns are shown. Based on the parameter set (see Table S3) for $\mathrm{Cm}^{3+}$ and $\mathrm{Bk}^{4+}$, we calculated the $\mu_{\text {eff }}$ vs $T$ plots and used a $\mathrm{Gd}^{3+}$ center as reference. In the case of $\mathrm{Cm}^{3+}$ (red line), the spin only approximation with $g=1.9261$ served as a comparison to the "full model" simulation. These examples show clearly the difference between the actinide and lanthanide systems in the $f^{7}$-configuration with a Russell-Saunders ${ }^{8} S_{7 / 2}$ ground state. A crystal field will not split the orbitally nondegenerate $S$ state. For the $4 f^{7}$-ion, $\mathrm{Gd}^{\mathrm{III}}$, it is indeed found that crystal-field splitting of the ground $J=7$ / 2 term is on the order of about $0.2 \mathrm{~cm}^{-1}$ with a corresponding $g$-value of 1.9993 (r.t. $\mu_{\text {eff }}=7.91 \mu_{\mathrm{B}}$; green line in Figure 9). The reason for this is that the mixing of excited-state wave functions into the ground state $\left(2.6 \%{ }^{6} \mathrm{P}_{7 / 2},\right) \cdot{ }^{112}$ However, the ground term for $\mathrm{Cm}^{3+}$ and $\mathrm{Bk}^{4+}$ are only $78 \%$ and $74 \%$ of ${ }^{8} S_{7 / 2}$

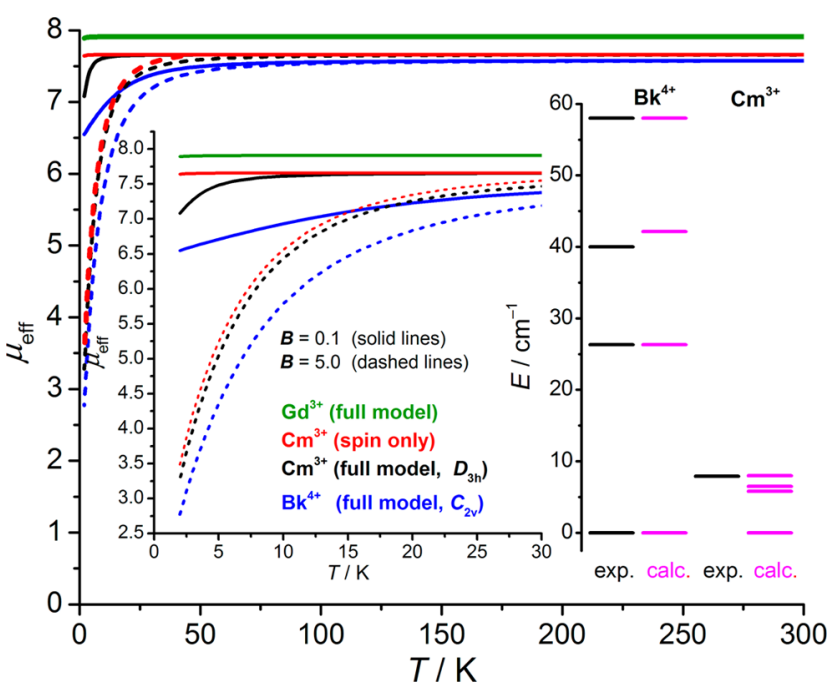

Figure 9. Variation $\mu_{\text {eff }}$ vs $\mathrm{T}$ of $\mathrm{Cm}^{3+}: \mathrm{LaCl}_{3}, \mathrm{Bk}^{4+}: \mathrm{CeF}_{4}$, and $\mathrm{Gd}^{3+}$ at applied magnetic fields $(\boldsymbol{B}=0.1$ and $5.0 \mathrm{~T}) . \mathrm{A} \mathrm{Gd}^{3+}$ center (green line) is used as reference. Inset: low temperature range (left), and ligand field splitting: exp. (black) and calc. (purple) $\mathrm{Cm}^{3+}: \mathrm{LaCl}_{3}$ and $\mathrm{Bk}^{4+}: \mathrm{CeF}_{4}$ (right).

because spin-orbit coupling mixes in substantial amounts of the ${ }^{6} \mathrm{P}_{7 / 2},{ }^{6} \mathrm{D}_{7 / 2}$, and higher terms that result in a reduced $\mu_{\text {eff }}$ value of $7.64 \mu_{\mathrm{B}}$ at room temperature.

In comparison with lanthanide $S$-state ions, much stronger spin-orbit coupling and reduced electrostatic interactions in concert with greater crystal-field interactions significantly change the characteristics of the ground state of the actinide $S$-state ion. The amount of the excited-state wave functions mixed into the ground state increases from $2.6 \%$ for $\mathrm{Gd}^{3+}$ to approximately $26 \%$ for $5 f^{7}$ systems ${ }^{110}$ depending on the strength of the single ion effects. The $g$-value for $4 f^{7}$ systems of 1.9993 is reduced because the spin-orbit-coupling interaction is two to three times larger in $5 f^{7}$-systems and creates a significantly reduced $g$-value of $1.9261\left(\mathrm{Cm}^{3+}\right)$ and $1.9134 \mathrm{Bk}^{4+}$, which leads to a reduced r.t. $\mu_{\text {eff }}$-value for $\mathrm{Cm}^{3+}$ $\left(\mu_{\text {eff }}=7.64\right)$ and $\mathrm{Bk}^{4+}\left(\mu_{\text {eff }}=7.59\right)$ (see Figure 9). As shown in the inset in Figure 9, $\mathrm{Bk}^{4+}$ compounds display stronger temperature dependence below $75 \mathrm{~K}$ in the $\mu_{\text {eff }}$ vs $T$ plot compared with $\mathrm{Cm}^{3+}$ compounds (below $25 \mathrm{~K}$ ) based on the larger ligand-field splitting and the different site symmetry at the actinide center. ${ }^{101,110}$ It also becomes evident that the spinonly model (red lines in Figure 9) for a $5 f^{7}$-system is not applicable for determining the magnetic properties in actinide complexes because the observed temperature dependence below $75 \mathrm{~K}$ is often incorrectly assigned to exchange interactions, but in fact is a consequence of single ion effects.

These effects are further augmented by varying the occupation of $m_{l}$ states of the ground states of $\mathrm{Gd}^{3+}, \mathrm{Cm}^{3+}$, and $\mathrm{Bk}^{4+}$ complexes as shown in Figure 10. In the case of the $\mathrm{Gd}^{3+}$ complexes nearly Curie behavior is observed down to $2 \mathrm{~K}$ (green line in Figure 10), a fact that is also reflected in the occupation of the $m_{1}$-values and every microstate is occupied by one electron ( $99 \%$ of electron density). In contrast, the actinides systems demonstrate totally different occupation of the $m_{l}$-values depending on the strength of the single ion effects. The occupation of the individual $m_{l}$-values range between $97 \%$ down to $77 \%$ and reflect a relatively large groundstate splitting in the $5 f^{7}$ ground term caused by the effects of the much larger spin-orbit coupling $\left(\mathrm{Gd}^{3+}, 1410 \mathrm{~cm}^{-1} ; \mathrm{Cm}^{3+}\right.$, 


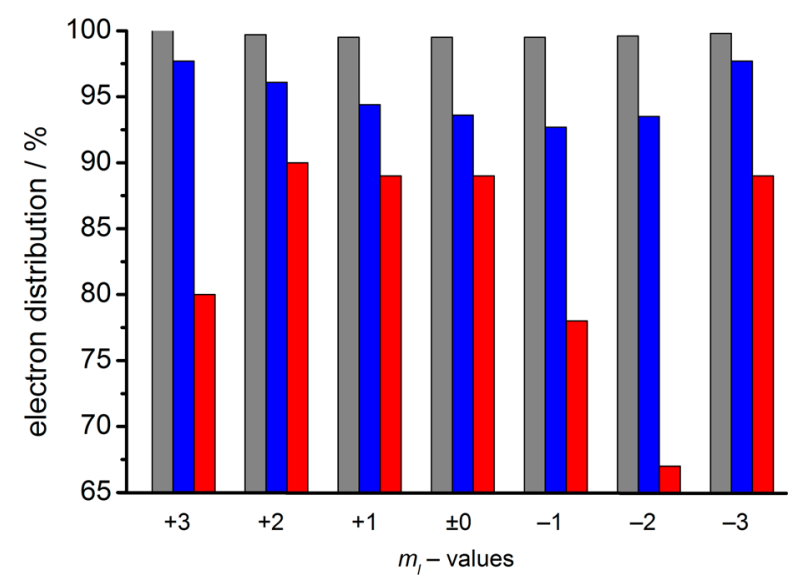

Figure 10. Electron distribution or occupation of the $m_{l}$ states for the ground state $\mathrm{Gd}^{3+}, \mathrm{Cm}^{3+}$ and $\mathrm{Bk}^{4+}$ (spin up component).

$2889 \mathrm{~cm}^{-1}$; $\left.\mathrm{Bk}^{4+}, 3150 \mathrm{~cm}^{-1}\right) .{ }^{101,110-112}$ This corresponds to nonspherically symmetric, i.e., anisotropic, ground state.

Density Functional Theory Calculations. In line with the previous studies on $\mathrm{Bk}(\mathrm{Hdpa})_{3}$ and $\mathrm{Bk}\left[\mathrm{B}_{6} \mathrm{O}_{8}(\mathrm{OH})_{5}\right]$, molecular DFT calculations on berkelium iodate clusters excised from the extended network were carried out prior to applying DFT band theory. The optimized geometries of these two clusters are in agreement with the experimental spatial arrangement (see Figure S4). First, a natural bonding orbital (NBO) analysis was carried out on the $\left[\mathrm{Bk}\left(\mathrm{IO}_{3}\right)_{7}\right]^{4-}$ and $\left[\mathrm{Bk}\left(\mathrm{IO}_{3}\right)_{8}\right]^{4-}$ clusters. In the latter, $\mathrm{NBO}$ analysis indicates six bonds with six oxygen atoms of the eight $\mathrm{IO}_{3}{ }^{-}$ligands, whereas surprisingly only one bond was found for the $\mathrm{Bk}^{\mathrm{III}}$ compound. The six bonds are strongly polarized toward O (90\%) and involve a $s-p-d-f$ atomic orbital mixture $\left(9 \% 7 \mathrm{~s}, 21 \% 7 \mathrm{p}, 29 \% 6 \mathrm{~d}\right.$, and $41 \% 5 \mathrm{f}$ ) from $\mathrm{Bk}^{\mathrm{IV}}$ (see Figure 11). Similarly, the computed Wiberg bond indexes are $\sim 0.5$, demonstrating that there is an important ionic part in the bonding in line with the polarization found. The spin density was also computed for the two complexes. For $\mathrm{Bk}^{\mathrm{IV}}$, there are 6.6 unpaired spins on Bk (7 expected) with 0.4 unpaired spins spread out over the oxygens of the $\mathrm{IO}_{3}{ }^{-}$ligands. In contrast, for the formally $\mathrm{Bk}^{\mathrm{III}}$ compound, the spin density is normal with eight unpaired electrons located in $5 f$ orbitals. As for $\mathrm{Bk}^{\mathrm{IV}}$, the bond found for $\mathrm{Bk}^{\mathrm{III}}$ is less polarized ( $52 \% \mathrm{Bk}$ and $48 \% \mathrm{O}$ ) with a berkelium's atomic orbital contribution to the bonding being $2 \% 7 s, 1 \% 7 p, 19 \% 6 d$, and $78 \% 5 f$. Therefore,
$\mathrm{Bk}^{\mathrm{IV}}$ is more covalent than $\mathrm{Bk}^{\mathrm{III}}$ and calculation on the $\mathrm{Cf}^{\mathrm{III}}$ analog was carried out for comparison. The bonding analysis is almost the same as the $\mathrm{Bk}^{\mathrm{III}}$ one. Indeed, NBO analysis indicates one bond that is strongly polarized $13 \%$ Cf- $87 \% \mathrm{O}$. The bond is mainly a $d / f$ mixture $(2 \% 7 s, 8 \% 7 p, 20 \% 6 d$, and $70 \% 5 f)$. Therefore, the bonding in $\mathrm{Cf}^{\mathrm{III}}$ and $\mathrm{Bk}^{\mathrm{III}}$ appear to be quite similar.

This difference in bonding between $\mathrm{Bk}^{\mathrm{III}} / \mathrm{Cf}^{\mathrm{III}}$ and $\mathrm{Bk}^{\mathrm{IV}}$ was investigated further using Quantum Theory Atoms In Molecule (QTAIM) analysis. This analysis indicates more bonds than NBO substantiated by the presence of 6 bond critical points (BCP) for $\mathrm{Bk}^{\mathrm{III}}$ and 7 for $\mathrm{Bk}^{\mathrm{IV}}$. The presence of more BCP for $\mathrm{Bk}^{\mathrm{IV}}$ than $\mathrm{Bk}^{\mathrm{III}}$ and $\mathrm{Cf}^{\mathrm{III}}$, in line with a greater covalency in the former found at the NBO level and in the same way, the fact that the number of $\mathrm{BCP}$ is the same for $\mathrm{Bk}^{\mathrm{III}}$ and $\mathrm{Cf}^{\mathrm{III}}$ is also in line with what found with NBO (Figure S5). Analyzing the $\mathrm{BCP}$ shows that the densities at those $\mathrm{BCP}$ are very small around 0.04 for $\mathrm{Bk}^{\mathrm{III}}$ and $\mathrm{Cf}^{\mathrm{II}}$ and around 0.08 for $\mathrm{Bk}^{\mathrm{IV}}$ (these values are close to what you get for hydrogen bonds in water cluster for 0.04 and strong hydrogen bonds in proteins for 0.08 ) with a positive laplacian (depletion of density). Therefore, the bonds are strongly polarized in line with what NBO found. The ellipticity is close to zero (0.05) in line with $\sigma$-type interactions. Therefore, these two density analyses are in line with the difference of covalency between $\mathrm{Bk}^{\mathrm{III}}$ and $\mathrm{Bk}^{\mathrm{IV}}$.

The question of a potential contribution of $\mathrm{Bk}^{\mathrm{III}}$ into $\mathrm{Bk}^{\mathrm{IV}}$, namely a multireference ground state for the latter that is also induced by spin-orbit coupling is still unclear so far due to this difference in bonding, and therefore $f$-in-core RECPs calculations were pursued where one can fix the oxidation state of a given metal center. These calculations clearly show that the $\mathrm{Bk}\left(\mathrm{IO}_{3}\right)_{8}$ structure is well-reproduced assuming a $\mathrm{Bk}^{\mathrm{IV}}$ as well as the $\mathrm{Bk}\left(\mathrm{IO}_{3}\right)_{7}$ one assuming $\mathrm{Bk}^{\mathrm{III}}$. However, interestingly enough, reoptimizing the $\mathrm{Bk}^{\mathrm{IV}}$ structure assuming a $\mathrm{Bk}^{\mathrm{III}}$ center yields the $\mathrm{Bk}^{\mathrm{III}}$ structure. Yet, computing a density analysis on the frozen optimized $\mathrm{Bk}^{\mathrm{IV}}$ structure assuming a $\mathrm{Bk}^{\mathrm{III}}$-type center leads to the bonding situation found for $\mathrm{Bk}^{\mathrm{IV}}$ with the original seven bonds. Therefore, the difference in covalency is primarily associated with the geometry more than the oxidation state. Indeed, in the $\mathrm{Bk}^{\mathrm{IV}}$ structure, the bonds are strongly polarized toward $\mathrm{O}$ and the $\mathrm{Bk}-\mathrm{O}$ bond distances are shorter (around $2.28 \AA$ ) for $\mathrm{Bk}^{\mathrm{IV}}$ than $\mathrm{Bk}^{\mathrm{III}}$ (around $2.46 \AA$ ). This roughly $0.2 \AA$ difference in bond length is just enough not to have overlap between $\mathrm{Bk}$ and $\mathrm{O}$ even if the orbital extension
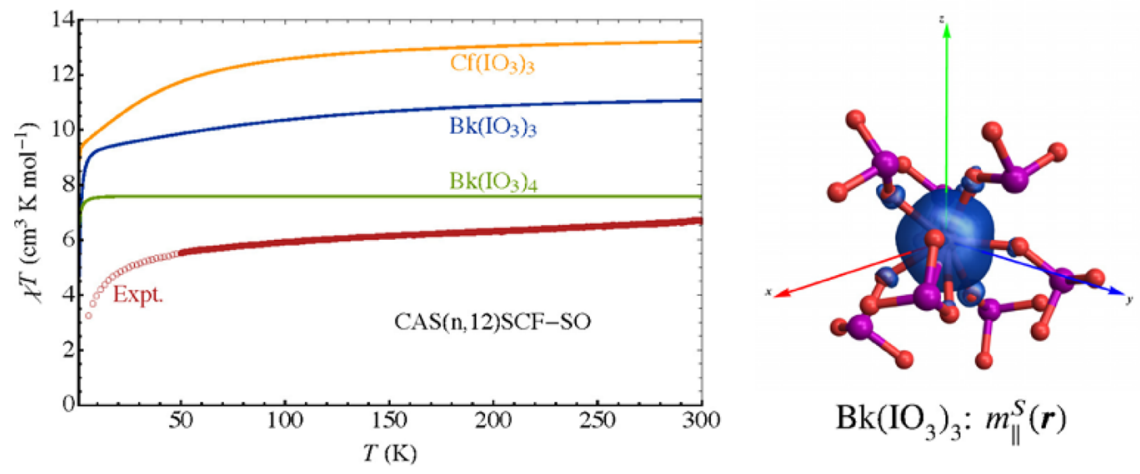

$$
\begin{array}{rrr}
\left\langle L_{\|}\right\rangle & =3.04 \\
\left\langle S_{\|}\right\rangle & =2.80 \\
g_{\|} & =17.32 \\
g_{\perp} & =0.00
\end{array}
$$

Figure 11. Calculated magnetic susceptibilities $\chi \mathrm{T}$ for cluster models of $\mathrm{Bk}\left(\mathrm{IO}_{3}\right)_{4}, \mathrm{Bk}\left(\mathrm{IO}_{3}\right)_{3}$, and $\mathrm{Cf}\left(\mathrm{IO}_{3}\right)_{3}$. CAS $(n, 12) \mathrm{SCF}-\mathrm{SO}$ calculations. The experimental $\chi \mathrm{T}$ of $\mathrm{Bk}\left(\mathrm{IO}_{3}\right)_{3}$ is also given for comparison. Spin $\left(\mathrm{m}_{\|}^{\mathrm{S}}\right)$ magnetization isosurface, orientation of the magnetization axes, and $g$-factors for the ground state doublet components with $S_{\|}>0$ along the magnetic axis $z$ of $\mathrm{Bk}\left(\mathrm{IO}_{3}\right)_{3}$, calculated using the method described in ref 41 . Isosurface value \pm 0.0005 au. 
Table 1. Calculated Energetic Splitting $\left(\mathrm{cm}^{-1}\right)$ between the Ground State and the First Excited State of Molecular Clusters of $\mathrm{Bk}\left(\mathrm{IO}_{3}\right)_{4}, \mathrm{Bk}\left(\mathrm{IO}_{3}\right)_{3}$, and $\mathrm{Cf}\left(\mathrm{IO}_{3}\right)_{3}{ }^{a}$

\begin{tabular}{|c|c|c|c|c|c|c|c|c|}
\hline & $\Delta E$ & weight of ${ }^{2 s+1} L_{J}$ & $g_{\|}$ & $g \perp$ & $\left\langle L_{\|}\right\rangle$ & $\left\langle S_{\|}\right\rangle$ & $\langle L \perp\rangle$ & $\langle S \perp\rangle$ \\
\hline \multicolumn{9}{|c|}{$\mathrm{Bk}\left(\mathrm{IO}_{3}\right)_{4}$} \\
\hline GS & 0.0 & $87.4{ }^{8} \mathrm{~S}_{7 / 2}$ & 1.95 & 7.89 & 0.02 & 0.48 & 0.07 & 1.93 \\
\hline ES & 1.4 & $87.4{ }^{8} \mathrm{~S}_{7 / 2}$ & 5.74 & 1.31 & 0.05 & 1.41 & 0.01 & 0.32 \\
\hline \multicolumn{9}{|c|}{$\mathrm{Bk}\left(\mathrm{IO}_{3}\right)_{3}$} \\
\hline GS & 0.0 & $85.6{ }^{7} \mathrm{~F}_{6}$ & 17.32 & 0.00 & 3.04 & 2.80 & 0.0 & 0.0 \\
\hline ES & 182.1 & $85.6^{7} \mathrm{~F}_{6}$ & & & & & & \\
\hline \multicolumn{9}{|c|}{$\mathrm{Cf}\left(\mathrm{IO}_{3}\right)_{3}$} \\
\hline GS & 0.0 & $82.9{ }^{6} \mathrm{H}_{15 / 2}$ & 17.16 & 0.75 & 4.83 & 2.05 & 0.19 & 0.09 \\
\hline ES & 86.3 & $82.9{ }^{6} \mathrm{H}_{15 / 2}$ & 11.85 & 3.29 & 3.10 & 1.41 & 0.86 & 0.39 \\
\hline
\end{tabular}

${ }^{a}$ CAS $(n, 12)$ SCF-SO results. The SO states are characterized in term of their corresponding ${ }^{2 s+1} L_{J}$ ion level. The calculated electronic $g$-factors, as well as the orbital $(\langle L\rangle)$ and spin $(\langle S\rangle)$ angular momentum expectation values for the projection along the magnetic axis $\|$ and in the perpendicular plane are given for comparison. The full calculated energetic splitting of the ${ }^{2 s+1} L_{J}$ levels are provided in the Supporting Information.
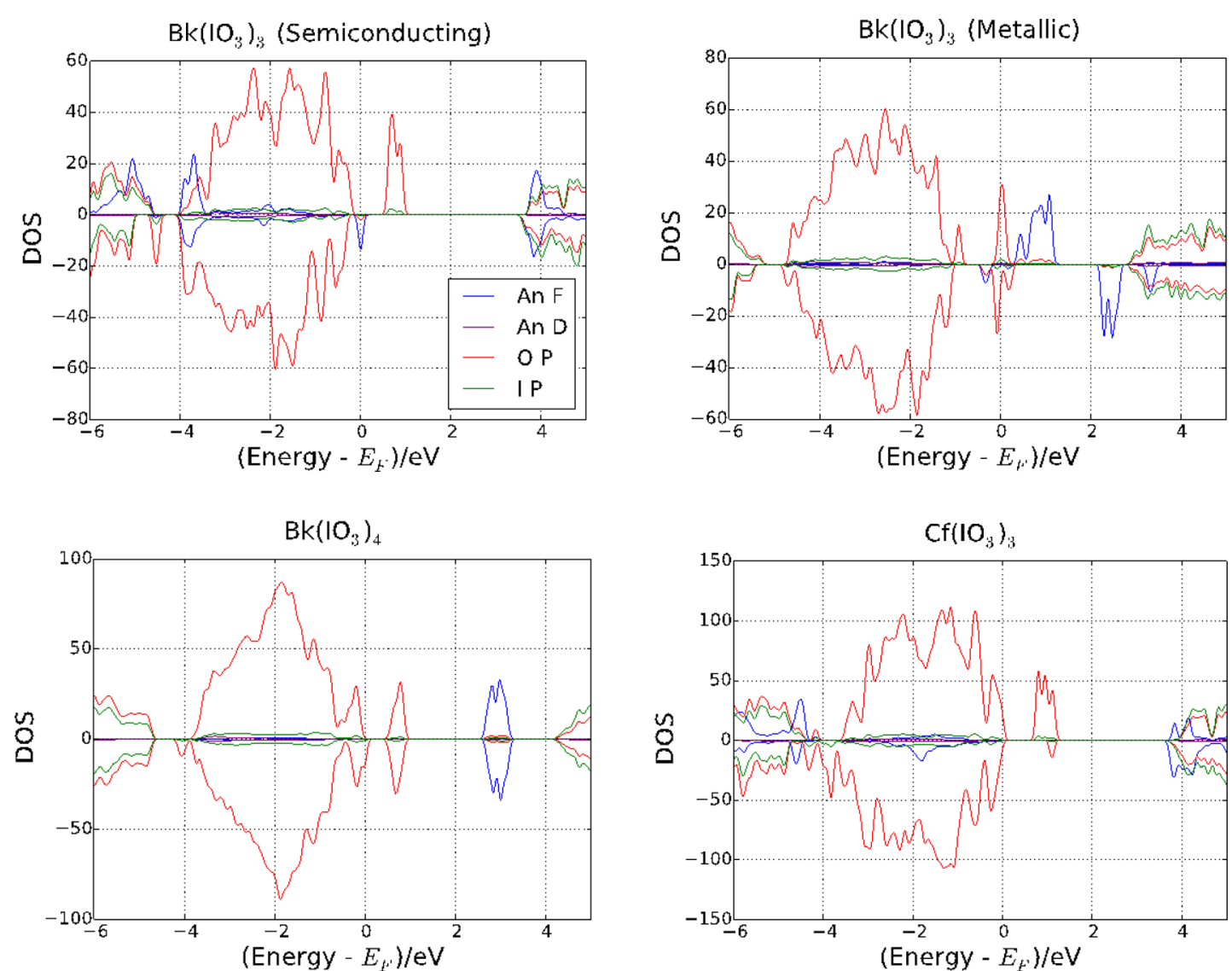

Figure 12. Projected density of states (PDOS) plots for $\mathrm{Bk}\left(\mathrm{IO}_{3}\right)_{3}, \mathrm{Bk}\left(\mathrm{IO}_{3}\right)_{4}$, and $\mathrm{Cf}\left(\mathrm{IO}_{3}\right)_{3}$.

in $\mathrm{Bk}^{\mathrm{III}}$ is slightly greater than in $\mathrm{Bk}^{\mathrm{IV}}$. Therefore, the structure and especially the $\mathrm{Bk}-\mathrm{O}$ distances are clearly associated with a $\mathrm{Bk}^{\mathrm{IV}}$ dominant contribution. Finally, for sake of comparison, calculations on the curium and americium analogs of $\mathrm{Bk}^{\mathrm{III}} / \mathrm{Cf}^{\mathrm{II}}$ compounds were carried out using several methods (vide supra). For curium, at the NBO level, no bond was found and there is no "covalency" in $\mathrm{Cm}\left(\mathrm{IO}_{3}\right)_{7}$. The bonds are purely ionic, and therefore berkelium is more Cf-like than $\mathrm{Cm}$. In contrast, for $\mathrm{Am}^{\mathrm{III}}$, the bonding situation is quite similar as what found for $\mathrm{Bk}^{\mathrm{III}}$ and $\mathrm{Cf}^{\mathrm{III}}$, and therefore quite different from $\mathrm{Cm}^{\mathrm{III}}$. Hence, $\mathrm{Am}^{\mathrm{III}}$ is slightly more covalent than $\mathrm{Cm}^{\mathrm{III}}$ and is consistent with the analyses presented herein.

CASSCF Calculations. The electronic structure and the magnetic properties of $\mathrm{Bk}\left(\mathrm{IO}_{3}\right)_{4}, \mathrm{Bk}\left(\mathrm{IO}_{3}\right)_{3}$, and $\mathrm{Cf}\left(\mathrm{IO}_{3}\right)_{3}$ clusters extracted from the crystal structures were also investigated using relativistic all-electron multireference wave function theory, including spin-orbit (SO) coupling (see Computational Details section). The calculated relative energies at the SCF-SO level between the ground state (GS) and the first excited state (ES) of the three complexes are given in Table 1. We point out that these, and the DFT calculations on the molecular clusters, represent an isolated complex picture of the systems, which allow us to study the chemical and magnetic properties of the complex theoretically without the presence of interactions that are specific to the solid. Deviations between the calculated and observed magnetic data, for instance, must therefore be attributed mainly to interactions within the solid, as the SCF-SO level of theory usually produces 
quite reliable magnetic susceptibilities. ${ }^{113-115}$ In the molecular cluster, the GS of $\mathrm{Bk}\left(\mathrm{IO}_{3}\right)_{4}$ corresponds to a Kramers doublet which derives from the ground level of the $\mathrm{Bk}^{\mathrm{IV}}$ ion ${ }^{8} S_{7 / 2}$, with $L=0, S=7 / 2$ and $J=L+S=7 / 2$. The nature of the GS and the total energetic splitting of the ${ }^{8} S_{7 / 2}$ level is sensitive to the size of the active space. When only the $5 f$ orbitals are in the active space, i.e., CAS $(7,7)$ SCF-SO, the total energetic splitting of the ${ }^{8} S_{7 / 2}$ level is $1044 \mathrm{~cm}^{-1}$ with the first excited state at 200 $\mathrm{cm}^{-1}$ above the GS (see Table S4). In this case, the GS has a strong magnetic anisotropy characterized by an easy axis of magnetization $\left(g_{\|}=11.66\right)$. The introduction of the $6 d$ orbitals in CAS $(7,12)$ SCF leads to a strong decrease of the energetic splitting of the ${ }^{8} S_{7 / 2}$ level. As shown in Table 1, the GS and the first excited state become effectively degenerate. The nature of the GS is also affected by the introduction of the $6 d$ orbitals in the active space, with a magnetic anisotropy that results now from an easy plane of magnetization $\left(g_{\perp}>g_{\|}\right)$. The small energetic splitting of the ${ }^{8} S_{7 / 2}$ level in combination with the large magnetic moment of the ground state leads to a magnetic susceptibility that reaches a saturation plateau at low temperatures (see Figure 12). At room temperature, the calculated magnetic susceptibility leads to a $\mu_{\text {eff }}=7.79 \mu_{\mathrm{B}}$, which is relatively close to the Hund's rule limit of $7.94 \mu_{\mathrm{B}}$. The small decrease of $\mu_{\text {eff }}$ is attributed to contribution from excited ${ }^{2 s+1} L_{J}$ ion levels in the wave function, and to a lesser extent to covalent interactions.

The natural orbitals (NOs) for the ground state are shown in Figure S4 of the Supporting Information. Note that the noninteger occupations are typical for multideterminant wave functions. As expected, the seven $5 f$ orbitals are essentially singly occupied and barely interact with the oxygen $2 p$ orbitals of the iodate ligands. A more pronounced hybridization is found between the formally empty $6 d$ orbitals and the oxygen $2 p$ orbitals. However, the electronic occupation of these orbitals remains very small ( 0.002 electrons each), indicating only weak ligand-metal covalency. This result may seem in contrast to the RECP and additional all-electron scalar relativistic DFT results (SI) for this complex, in which the $5 f$ orbitals mix with the oxygen $2 p$ orbitals of the iodate ligands (see Figure 11). There may be a difference because of a too localized HartreeFock like behavior in the CASSCF calculations vs a delocalization error that may lead to too covalent ligandmetal interactions in the DFT calculation. However, the observation that the $\mathrm{Bk}^{\mathrm{III}}$ and $\mathrm{Bk}^{\mathrm{IV}}$ structures are well reproduced with $5 f$-in-core pseudopotential DFT calculations, where no bonding with the $5 f$ shell can take place, suggests that mixing between metal and ligand orbitals may occur in the calculations without much of an energetic stabilization and the DFT and CASSCF cluster model calculations are ultimately not in disagreement.

The GS of the $\mathrm{Bk}\left(\mathrm{IO}_{3}\right)_{3}$ cluster model corresponds to a nonKramers doublet. This doublet derives principally from the ground level ${ }^{7} F_{6}$ of the free $\mathrm{Bk}^{\mathrm{III}}$ ion, with $L=3, S=3$, and $J=$ $L+S=6$. Contrary to $\mathrm{Bk}\left(\mathrm{IO}_{3}\right)_{4}$, the energetic splitting of the ${ }^{7} F_{6}$ level is hardly affected by the chosen active space (see Table S5 of SI). The total energetic splitting of the ${ }^{7} F_{6}$ level is 1783 $\mathrm{cm}^{-1}$ with the first excited state at $182 \mathrm{~cm}^{-1}$ above the GS at the SCF-SO level. The GS exhibits a large magnetic anisotropy with $g_{\|}=17.7$ and $g_{\perp}=0.0$. The calculated magnetic susceptibility is shown in Figure 11. At room temperature, the calculations give $\mu_{\text {eff }}=9.41 \mu_{\mathrm{B}}$, which is very close to the expected value for a pure ${ }^{7} F_{6}$ level $\left(\mu_{\text {eff }}=9.72 \mu_{\mathrm{B}}\right)$. As shown in Figure 12, the calculated susceptibility for the cluster model differs from the experimental measurement on the solid. This deviation between theory and experiment is presently not understood. A possibility is that the $\mathrm{Bk}\left(\mathrm{IO}_{3}\right)_{3}$ sample decomposed during the time of the measurements. The NOs of the GS are shown in Figure S5. The extra electron, compared to $\mathrm{Bk}^{\mathrm{IV}}$, is distributed mainly among the two $5 f_{\phi}$ orbitals. The $6 d$ occupations are slightly larger than those of the $\mathrm{Bk}\left(\mathrm{IO}_{3}\right)_{4}$ complex. These CAS orbitals are found in good agreement with the orbitals obtained by the all-electron DFT calculations that exhibit some, but not strong, $5 f-2 p$ hybridization (see Figure S8).

Similarly to $\mathrm{Bk}\left(\mathrm{IO}_{3}\right)_{4}$, the GS of $\mathrm{Cf}\left(\mathrm{IO}_{3}\right)_{3}$ corresponds to a Kramers doublet that derives from the ${ }^{6} \mathrm{H}_{15 / 2}$ level of the free $\mathrm{Cf}^{\mathrm{III}}$ ion, with $L=5, S=5 / 2$, and $J=L+S=15 / 2$. The total energetic splitting of the ${ }^{6} \mathrm{H}_{15 / 2}$ level is $1376 \mathrm{~cm}^{-1}$ with the first excited state at $86 \mathrm{~cm}^{-1}$ above the GS (see Table S7). This energetic splitting was found hardly affected by the size of the active space. The NOs of the GS are shown in Figures S6-S8 and reveal that the $5 f$ orbitals remain principally nonbonding in character in this set of calculations.

Solid-State DFT Calculations. We have also carried out calculations with periodic boundary conditions with the HeydScuseria-Ernzerhof (HSE) functional on the crystal structures of $\mathrm{Bk}\left(\mathrm{IO}_{3}\right)_{3}, \mathrm{Bk}\left(\mathrm{IO}_{3}\right)_{4}$, and $\mathrm{Cf}\left(\mathrm{IO}_{3}\right)_{3}{ }^{71}$ Projected density of states (PDOS) plots obtained from these calculations are shown in Figure 12. In these plots, the Fermi energy is defined to be zero and the DOS of the $\alpha$ (spin-up) and $\beta$ (spin-down) states are shown as positive and negative, respectively. For $\mathrm{Bk}\left(\mathrm{IO}_{3}\right)_{3}$, two solutions close in energy (differing by 9 milihartree only) were found: one semiconducting having a band gap of $0.86 \mathrm{eV}$, and another one metallic. More precisely, the latter is half-metallic, although the gap for the $\beta$ states is small $(0.18 \mathrm{eV})$. The near degeneracy between the semiconducting and metallic sates of $\mathrm{Bk}\left(\mathrm{IO}_{3}\right)_{3}$ may indeed be a real effect: the series of actinide oxides displays a localized (Mott) insulator to metal crossover around $\mathrm{Cm}$, with heavier compounds becoming charge-transfer insulators. ${ }^{72}$ We note, however, that our calculations do not take into account spinorbit coupling, and that metallic character may dissapear by inclusion of such effects. The magnetic moments estimated using Mulliken populations and the expectation value of $S^{2}$ from the Kohn-Sham determinant for both the semiconducting $\left(7.1 \mu_{\mathrm{B}}\right)$ and metallic $\left(5.8 \mu_{\mathrm{B}}\right)$ states agree well with the reduced magnetic moment observed experimentally $\left(6.8 \mu_{\mathrm{B}}\right)$. Both solutions display Néel-type ferrimagnetic ordering, with the spins in neighboring $\mathrm{Bk}$ atoms aligning in opposite directions imperfectly (as opposed to an antiferromagnet with exact cancellation of spins); the sum of Mulliken spin densities in neighboring Bk atoms is 5.9 and 0.0 for the semiconductor state, and 5.9 and -6.4 for the metallic one. It is also interesting that, for semiconducting $\mathrm{Bk}\left(\mathrm{IO}_{3}\right)_{3}$, the oxygen $\alpha 2 p$ states are solely responsible for the smal gap; the band gap for $\beta$ states is much larger $(3.5 \mathrm{eV})$. This behavior is caused by the Bk center taking $\alpha$ electrons from the $2 p$ orbitals of oxygen.

Antiferromagnetic structure can be appreciated in the PDOS of $\mathrm{Bk}\left(\mathrm{IO}_{3}\right)_{4}$. This corresponds to a Néel-type antiferromagnetic ordering with spins alternating directions for $\mathrm{Bk}$ atoms in adjacent unit cells in one direction; the Mulliken spin densities for two such nearest Bk atoms are +6.5 and -6.5 . HSE predicts an effective magnetic moment of $6.6 \mu_{\mathrm{B}}$ for this strucure, which is in good agreement with the experimental measurements. With an indirect gap of $0.53 \mathrm{eV}, \mathrm{Bk}\left(\mathrm{IO}_{3}\right)_{4}$ is also predicted to be semiconducting. The DOS of $\mathrm{Cf}\left(\mathrm{IO}_{3}\right)_{3}$ displays similar 
features to the semiconducting $\mathrm{Bk}\left(\mathrm{IO}_{3}\right)_{3}$ : a small gap for $\alpha$ states $(0.78 \mathrm{eV})$, and a larger gap for $\beta$ states. As occurs also in $\mathrm{Bk}\left(\mathrm{IO}_{3}\right)_{3}$, the $\mathrm{Cf}$ takes $\alpha$ electrons from the $2 p$ orbitals of oxygen. The effective magnetic moment of $\mathrm{Cf}\left(\mathrm{IO}_{3}\right)_{3}$ is also close to that of $\mathrm{Bk}\left(\mathrm{IO}_{3}\right)_{3}\left(7.0 \mu_{\mathrm{B}}\right)$. These similarities are in line with those observed between $\mathrm{Bk}^{\mathrm{III}}$ and $\mathrm{Cf}^{\mathrm{II}}$ compounds in our molecular calculations. Note that, in all cases shown in Figure 12 , the chemistry is dominated by the oxygen $2 p$ states. However, there is significant overlap between actinide $5 f$ orbitals, and the $p$ states of iodine and oxygen, which suggests covalency in these compounds. Finally, we must note that all the compounds are predicted to have narrow band gaps, and that spin-orbit coupling (not considered here) may widen these gaps. Nonetheless, HSE is typically very accurate for gaps in the range of those calculated here. ${ }^{71-73}$

$\left[\mathrm{BkCl}_{6}\right]^{3-}$ and $\left[\mathrm{BkCl}_{6}\right]^{2-}$ as Benchmark Molecules. The electronic structures of $\mathrm{Bk}^{\mathrm{III}}$ and $\mathrm{Bk}^{\mathrm{IV}}$ in an octahedral environment were studied with the aim of using them as benchmarks for more complex systems, such those previously described in this work. This allows for the evaluation of the main differences between both oxidation states in similar compounds with the symmetry advantage of the inversion center avoiding the mixing between $5 f$ and $6 d$ orbitals. All these calculations were based on multiconfigurational CASSCF/ NEVPT2 wave function corrected by spin-orbit coupling (further information in Computational Details). Three active spaces were selected in order to analyze the influence of the $3 p$ subshell of the ligands $\left(t_{1 u}\right.$ and $\left.t_{2 u}\right)$ and the $6 d$ subshell of the metal by means of the CAS $[n, 10]$ SCF $\left(n=14 \mathrm{Bk}^{\mathrm{III}} n=13\right.$ $\left.\mathrm{Bk}^{\mathrm{IV}}\right)$ and the CAS $[n, 12] \mathrm{SCF}\left(n=8 \mathrm{Bk}^{\mathrm{III}} n=7 \mathrm{Bk}^{\mathrm{IV}}\right)$, respectively. Independently of the selected active space, all of them were capable to reproduce the spin-free (SF) states, namely the splitting of the ${ }^{7} \mathrm{~F}_{6}$ atomic term for $\mathrm{Bk}^{\mathrm{III}}$ into the ${ }^{7} \mathrm{~A}_{2 \mathrm{u}}<{ }^{7} \mathrm{~T}_{2 \mathrm{u}}<{ }^{7} \mathrm{~T}_{1 \mathrm{u}}$ terms, and the unsplitted ${ }^{8} \mathrm{~S}_{7 / 2}$ atomic term correspondig to the ${ }^{8} \mathrm{~A}_{1 \mathrm{~g}}$ ground term for $\mathrm{Bk}^{\mathrm{IV}}$.

The SF states give the first difference between both oxidation states from the covalency point of view. The ground state configuration was $100 \%\left[\mathrm{t}^{6} 5 \mathrm{f}^{8}\right]$ of the trivalent ion for both $t_{1 u}$ and $t_{2 u}$ symmetry. In contrast, the tetravalent ion presents a strong multideterminantal character in their SF ground state. If $t_{1 u}$ orbitals are considered the configuration of this state is $90 \%$ $\left[\mathrm{t}_{1 \mathrm{u}}{ }^{6} 5 \mathrm{f}^{7}\right]+10 \%\left[\mathrm{t}_{1 \mathrm{u}} 5 \mathrm{f}^{8}\right]$ and if $\mathrm{t}_{2 \mathrm{u}}$ orbitals are considered the resulting configuration is $85 \%\left[\mathrm{t}_{2 \mathrm{u}}{ }^{6} 5 \mathrm{f}^{7}\right]+15 \%\left[\mathrm{t}_{2 \mathrm{u}}{ }^{5} 5 \mathrm{f}^{8}\right]$. It is important to notice that the absolute energy of the former is lower than the latter by $\sim 1.4 \mathrm{eV}$. The contributions of singleexcited configurations into the ground state are evidence of the covalent character of ligand-metal bonding. The natural orbital occupation numbers reinforce the idea of the more covalent character of $\mathrm{Bk}^{\mathrm{IV}}$ respect to $\mathrm{Bk}$. Traditionally, a covalent bond is described by a doubly occupied bonding orbital; however, this is a picture of bonding in a single-determinant scenario. A correlated multideterminantal wave function may reflect large contributions from various different molecular orbital configurations. A suitable description of bonding in such situation may then be obtaining with pairs of bonding and antibonding orbitals that are both fractionally occupied. This can be seen in the $\mathrm{Bk}^{\mathrm{IV}}$ molecule by the noninteger occupation of the $\mathrm{t}_{1 \mathrm{u}}\left(\mathrm{t}_{2 \mathrm{u}}\right)$ natural bonding orbitals 1.69 (1.66) and antibonding orbitals, with a large contribution from the $5 f$ subshell, $1.16(1.20)$. On the other hand, $\mathrm{Bk}^{\mathrm{III}}$ shows higher occupation numbers nearer to 1.90 , corroborating the less covalent character in this case. Moreover, the nature of bonding is evidenced by the strong electron donation from ligands to metal. This donation in $\mathrm{Bk}^{\mathrm{IV}}$ is $\sim 1.0 \mathrm{e}^{-}$and only $\sim 0.33 \mathrm{e}^{-}$in $\mathrm{Bk}^{\mathrm{III}}$.

From the inclusion of spin-orbit coupling, which allows the mixing of the SF states, it is possible to observe a multireference character of the ground state for $\mathrm{Bk}^{\mathrm{IV}}$ corresponding to only an $84 \%$ of ${ }^{8} \mathrm{~A}_{1 \mathrm{~g}}$ contribution and the remaining $16 \%$ coming from excited sextet states that increase by $\sim 12 \%$ in the involvement of configuration of the type $\left[\mathrm{t}_{1 \mathrm{u}} 5 \mathrm{f}^{8}\right]$. This situation is not the case for $\mathrm{Bk}^{\mathrm{III}}$ where the SO ground state corresponds to a $100 \%$ of ${ }^{7} \mathrm{~F}_{6}$ multiplet. This endorses not only the more covalent character of the $\mathrm{Bk}^{\mathrm{IV}}$ but also the $\mathrm{SO}$ effect upon this molecular property.

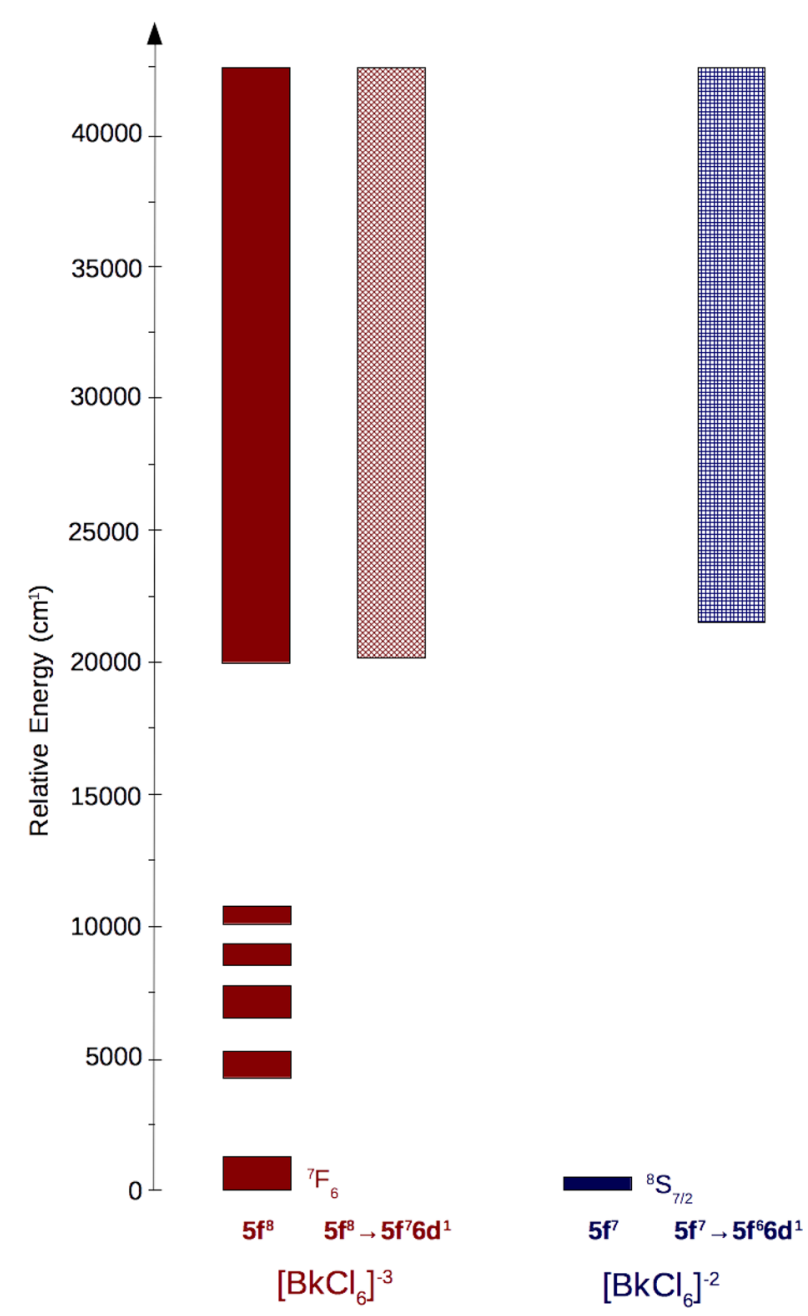

Figure 13. Electronic states of trivalent (red wine/red wine dashed blocks) and tetravalent (dark blue/dark blue dashed blocks) berkelium hexahalide ions including. Solid blocks correspond to $5 f \rightarrow 5 f$ transitions while dashed blocks correspond to $5 f \rightarrow 6 d$. In the case of $\mathrm{Bk}^{3+}$ the block located at $\sim 20.000 \mathrm{~cm}^{-1}$ corresponds to $5 f$ (septuplet) $\rightarrow 5 f$ (quintuplet).

Finally, the inclusion of the $6 d$ subshell into the active space was considered in order to obtain information about the $f-d$ transitions. First, we looked at the ground state and the effect of the inclusion of the $6 d$ subshell was negligible in both tri- and tetravalent cases. This means that the electronic states arrangement was not affected by the inclusion of this subshell (see Table S7). On the other hand, the inclusion of dynamic correlation allow us to reproduce the electronic spectrum of the $\mathrm{Bk}^{\mathrm{III}}$ compound in accordance with experimental values 
reported elsewhere $\left(\sim 20.000-40.000 \mathrm{~cm}^{-1}\right)$ as shown Figure 13. ${ }^{19,21,33,34}$ The electronic state arrangement obtained by our calculations do not differs grossly from those previously reported, ${ }^{19,21,33,34}$ indicating that the optical spectrum is relatively weakly affected by the ligand field. Therefore, based on the charge transfer from the chlorides to $\mathrm{Bk}^{\mathrm{IV}}$ regarding $\mathrm{Bk}^{\mathrm{III}}$, we believe that in late actinides, such as berkelium, the formal oxidation state term should be used carefully due to the metal center in the tetravalent state having non-negligible $5 f^{8}$ character. In this context, it is possible to believe that an intervalence state could be observed in $\mathrm{Bk}^{\mathrm{IV}}$ samples.

\section{CONCLUSIONS}

In this work, we have described a number of unanticipated results that were initiated with the successful preparation of $\mathrm{Bk}\left(\mathrm{IO}_{3}\right)_{3}$ and $\mathrm{Bk}\left(\mathrm{IO}_{3}\right)_{4}$. These compounds represent only the third and fourth single crystal structures for berkelium and the only $\mathrm{Bk}^{\mathrm{IV}}$ structure currently known. We have shown that initially $\mathrm{Bk}\left(\mathrm{IO}_{3}\right)_{4}$ contains trace amounts of $\mathrm{Bk}^{\mathrm{III}}$ whose signature is observed in the photoluminescence spectra. The presence of $\mathrm{Bk}^{\mathrm{III}}$ in this sample gives rise to a low-energy absorption feature that is consistent with intervalence charge transfer. However, the high-specific activity of ${ }^{249} \mathrm{Bk}$ causes oxidation of the mixed-valent $\mathrm{Bk}^{\mathrm{III}} / \mathrm{Bk}^{\mathrm{IV}}$ state to only $\mathrm{Bk}^{\mathrm{IV}}$. The focal point of this work is the observation of an asymmetric ground state present in $\mathrm{Bk}^{\mathrm{IV}}$ even though it possesses a halffilled $5 f$ orbital. The reasons that this ground state does not adhere to the simple rules provided by Russell-Saunders coupling and Hund's Rule are 3-fold. First, rather than having a state that is simply composed of one electron in each microstate with the same spin orientation, some of the spin has the opposite orientation. Second, spin-orbit coupling mixes low-lying excited states with the ground state, and thus some of the spin density lies in these excited states. Third, there is some degree of covalency in the $\mathrm{Bk}^{\mathrm{IV}}-\mathrm{O}$ bonds that distributes the $5 f$ electrons onto the ligands. These factors are absent in $\mathrm{Gd}^{\mathrm{III}}$ and substantially diminished even in $\mathrm{Cm}^{\mathrm{III}}$.

\section{ASSOCIATED CONTENT}

\section{S Supporting Information}

The Supporting Information is available free of charge on the ACS Publications website at DOI: 10.1021/jacs.7b05569.

Crystallographic information, magnetochemical parameters, and computational details (PDF)

Data for $\mathrm{I}_{2} \mathrm{O}_{6}, 4\left(\mathrm{IO}_{3}\right), 2(\mathrm{Bk})(\mathrm{CIF})$

\section{AUTHOR INFORMATION}

\section{Corresponding Author}

*albrecht-schmitt@chem.fsu.edu

\section{ORCID 1}

Kenneth Hanson: 0000-0001-7219-7808

Frédéric Gendron: 0000-0002-1896-3978

Jochen Autschbach: 0000-0001-9392-877X

Laurent Maron: 0000-0003-2653-8557

Paul Kögerler: 0000-0001-7831-3953

Cristian Celis-Barros: 0000-0002-4685-5229

Dayán Páez-Hernández: 0000-0003-2747-9982

Thomas E. Albrecht-Schmitt: 0000-0002-2989-3311

Notes

The authors declare no competing financial interest.

\section{ACKNOWLEDGMENTS}

This material is based upon work supported by the U.S. Department of Energy, Office of Science, Office of Basic Energy Sciences, Heavy Elements Chemistry Program, under Award Numbers DE-FG02-13ER16414 (FSU), DE-SC0001136 (formerly DE-FG02-09ER16066) (FG \& JA), and DE-FG0204ER15523 (G.E.S). G.E.S. is a Welch Foundation Chair (Grant No. C-0036). The isotopes used in this research were supplied by the U.S. Department of Energy, Office of Science, by the Isotope Program in the Office of Nuclear Physics. The ${ }^{249} \mathrm{Bk}$ was provided to Florida State University by the Isotope Development and Production for Research and Applications Program through the Radiochemical Engineering and Development Center at Oak Ridge National Laboratory. Magnetization measurements using the VSM SQUID MPMS were performed at the National High Magnetic Field Laboratory, which is supported by National Science Foundation Cooperative Agreement No. DMR-1157490, the State of Florida, and the U.S. Department of Energy. This research is supported in part by an appointment to the CBFO Fellowship Program (MAS), sponsored by the U.S. Department of Energy and administered by the Oak Ridge Institute for Science and Education. Jamie Wang is supported by the National Science Foundation Graduate Research Fellowship under Grant No. DGE-1449440.

\section{REFERENCES}

(1) Nugent, L. J.; Baybarz, R. D.; Burnett, J. L.; Ryan, J. L. J. Phys. Chem. 1973, 77, 1528-1539.

(2) Crosswhite, H. M.; Crosswhite, H.; Carnall, W. T.; Paszek, A. P. J. Chem. Phys. 1980, 72, 5103-5117.

(3) MacDonald, M. R.; Bates, J. E.; Ziller, J. W.; Furche, F.; Evans, W. J. J. Am. Chem. Soc. 2013, 135, 9857-9868.

(4) Fieser, M. E.; MacDonald, M. R.; Krull, B. T.; Bates, J. E.; Ziller, J. W.; Furche, F.; Evans, W. J. J. Am. Chem. Soc. 2015, 137, 369-382.

(5) Duignan, T. J.; Autschbach, J. J. Chem. Theory Comput. 2016, 12, 3109-3121.

(6) Löble, M. W.; Keith, J. M.; Altman, A. B.; Stieber, S. C. E.; Batista, E. R.; Boland, K. S.; Conradson, S. D.; Clark, D. L.; LezamaPacheco, J.; Kozimor, S. A.; Martin, R. L.; Minasian, S. G.; Olson, A. C.; Scott, B. L.; Shuh, D. K.; Tyliszczak, T.; Wilkerson, M. P.; Zehnder, R. A. J. Am. Chem. Soc. 2015, 137, 2506-2523.

(7) Altman, A. B.; Pacold, J. I.; Wang, J.; Lukens, W. W.; Minasian, S. G. Dalton Trans. 2016, 45, 9948-9961.

(8) Spitsyn, V. I.; Gelman, A. D.; Krot, N. N.; Mefodiyeva, M. P.; Zakharova, F. A.; Komkov, Yu. A.; Shilov, V. P.; Smirnova, I. V. J. Inorg. Nucl. Chem. 1969, 31, 2733-2745.

(9) Burns, J. H.; Baldwin, W. H.; Stokely, J. R. Inorg. Chem. 1973, 12, 466-469.

(10) Williams, C. W.; Blaudeau, J. P.; Sullivan, J. C.; Antonio, M. R.; Bursten, B.; Soderholm, L. J. Am. Chem. Soc. 2001, 123, 4346-4347.

(11) Grigoriev, M. S.; Krot, N. N. Acta Crystallogr., Sect. C: Cryst. Struct. Commun. 2009, 65, i91-i93.

(12) Conradson, S. D.; Abney, K. D.; Begg, B. D.; Brady, E. D.; Clark, D. L.; den Auwer, C.; Haire, R. G. Inorg. Chem. 2004, 43, 116-131.

(13) Nikonov, M. V.; Gogolev, A. V.; Tananaev, I. G.; Myasoedov, B. F. Radiochemistry 2004, 46, 340-342.

(14) Hobart, D. E.; Samhoun, K.; Peterson, J. R. Radiochim. Acta 1982, 31, 139-146.

(15) Baybarz, R. D.; Asprey, L. B.; Strouse, C. E.; Fukushima, E. J. Inorg. Nucl. Chem. 1972, 34, 3427-3431.

(16) Silva, R. J.; Sikkeland, T.; Nurmia, M.; Ghiorso, A.; Hulet, E. K. J. Inorg. Nucl. Chem. 1969, 31, 3405-3409.

(17) Stokely, J. R.; Baybarz, R. D.; Peterson, J. R. J. Inorg. Nucl. Chem. 1972, 34, 392-393.

(18) Fardy, J. J.; Weaver, B. Anal. Chem. 1969, 41, 1299-1302. 
(19) Deblonde, G. J.-P.; Sturzbecher-Hoehne, M.; Rupert, P. B.; An, D. D.; Illy, M.-C.; Ralston, C. Y.; Brabec, J.; de Jong, W. A.; Strong, R. K.; Abergel, R. J. Nat. Chem. 2017, 9, 843.

(20) Szigethy, G.; Xu, J.; Gorden, A. E.; Teat, S. J.; Shuh, D. K.; Raymond, K. N. Eur. J. Inorg. Chem. 2008, 13, 2143-2147.

(21) Silver, M. A.; Cary, S. K.; Johnson, J. A.; Baumbach, R. E.; Arico, A. A.; Luckey, M.; Urban, M.; Wang, J. C.; Polinski, M. J.; Chemey, A.; Liu, G.; Chen, K.-W.; Van Cleve, S. M.; Marsh, M. L.; Eaton, T. M.; van de Burgt, B.; Gray, A. L.; Hobart, D. E.; Hanson, K.; Maron, L.; Gendron, F.; Autschbach, J.; Speldrich, M.; Kögerler, P.; Yang, P.; Braley, J.; Albrecht-Schmitt, T. E. Science 2016, 353, 888-894.

(22) Laubereau, P. G.; Burns, J. H. Inorg. Chem. 1970, 9, 1091-1095.

(23) Ferrier, M. G.; Batista, E. R.; Berg, J. M.; Birnbaum, E. R.; Cross, J. N.; Engle, J. W.; La Pierre, H. S.; Kozimor, S. A.; Pacheco, J. S. L.; Stein, B. W.; Stieber, S. C. E.; Wilson, J. J. Nat. Commun. 2016, 7, 12312 .

(24) Polinski, M. J.; Cross, J. N.; Villa, E. M.; Lin, J.; Alekseev, E. V.; Depmeier, W.; Albrecht-Schmitt, T. E. Inorg. Chem. 2013, 52, 80998105.

(25) Jin, G. B.; Choi, E. S.; Albrecht-Schmitt, T. E. J. Solid State Chem. 2009, 182, 1075-1081.

(26) Soderholm, L.; Skanthakumar, S.; Williams, C. W. Phys. Rev. B: Condens. Matter Mater. Phys. 1999, 60, 4302-4308.

(27) Cunningham, B. B.; Feay, D. C.; Rollier, M. A. J. Am. Chem. Soc. 1954, 76, 3361-3363.

(28) Largeau, E.; El-Ghozzi, M.; Avignant, D. J. Solid State Chem. 1998, 139, 248-258.

(29) Morss, L. R.; Richardson, J. W.; Williams, C. W.; Lander, G. H.; Lawson, A. C.; Edelstein, N. M.; Shalimoff, G. V. J. Less-Common Met. 1989, 156, 273-289.

(30) Niikura, F.; Hotta, T. Phys. Rev. B: Condens. Matter Mater. Phys. 2011, 83, 172402 .

(31) Sheldrick, G. M. Acta Crystallogr., Sect. A: Found. Adv. 2015, 71, $3-8$.

(32) Spek, A. L. Acta Crystallogr., Sect. D: Biol. Crystallogr. 2009, 65, 148-155.

(33) Carnall, W. T.; Beitz, J. V.; Crosswhite, H. J. Chem. Phys. 1984, $80,2301-2308$.

(34) Carnall, W. T. J. Chem. Phys. 1992, 96, 8713-8726.

(35) Becke, A. D. J. Chem. Phys. 1993, 98, 5648-5652.

(36) Perdew, J. P.; Wang, Y. Phys. Rev. B: Condens. Matter Mater. Phys. 1992, 45, 13244-13249.

(37) Küchle, W.; Dolg, M.; Stoll, H.; Preuß, H. J. Chem. Phys. 1994, $100,7535-7543$.

(38) Cao, X. Y.; Dolg, M.; Stoll, H. J. Chem. Phys. 2003, 118, 487497.

(39) Cao, X.; Dolg, M. J. Mol. Struct.: THEOCHEM 2004, 673, 203209.

(40) Moritz, A.; Cao, X. Y.; Dolg, M. Theor. Chem. Acc. 2007, 118, 845-854.

(41) Bergner, A.; Dolg, M.; Kuechle, W.; Stoll, H.; Preuss, H. Mol. Phys. 1993, 80, 1431.

(42) Martin, J. M. L.; Sundermann, A. J. Chem. Phys. 2001, 114, 3408.

(43) Maron, L.; Teichteil, C. Chem. Phys. 1998, 237, 105-122.

(44) Hehre, W. J.; Ditchfield, R.; Pople, J. A. J. Chem. Phys. 1972, 56, 2257-2261.

(45) Hariharan, P. C.; Pople, J. A. Theor. Chim. Acta 1973, 28, 213222.

(46) Binkley, J. S.; Pople, J. A.; Hehre, W. J. J. Am. Chem. Soc. 1980, 102, 939-947.

(47) Frisch, M. J.; Trucks, G. W.; Schlegel, H. B.; Scuseria, G. E.; Robb, M. A.; Cheeseman, J. R.; Scalmani, G.; Barone, V.; Mennucci, B.; Petersson, G. A.; Nakatsuji, H.; Caricato, M.; Li, X.; Hratchian, H. P.; Izmaylov, A. F.; Bloino, J.; Zheng, G.; Sonnenberg, J. L.; Hada, M.; Ehara, M.; Toyota, K.; Fukuda, R.; Hasegawa, J.; Ishida, M.; Nakajima, T.; Honda, Y.; Kitao, O.; Nakai, H.; Vreven, T.; Montgomery, J. A., Jr.; Peralta, J. E.; Ogliaro, F.; Bearpark, M.; Heyd, J. J.; Brothers, E.; Kudin, K. N.; Staroverov, V. N.; Kobayashi, R.; Normand, J.; Raghavachari, K.; Rendell, A.; Burant, J. C.; Iyengar, S. S.; Tomasi, J.; Cossi, M.; Rega,
N.; Millam, J. M.; Klene, M.; Knox, J. E.; Cross, J. B.; Bakken, V.; Adamo, C.; Jaramillo, J.; Gomperts, R.; Stratmann, R. E.; Yazyev, O.; Austin, A. J.; Cammi, R.; Pomelli, C.; Ochterski, J. W.; Martin, R. L.; Morokuma, K.; Zakrzewski, V. G.; Voth, G. A.; Salvador, P.; Dannenberg, J. J.; Dapprich, S.; Daniels, A. D.; Farkas, O.; Foresman, J. B.; Ortiz, J. V.; Cioslowski, J.; Fox, D. J. Gaussian 09, Revision D.01; Gaussian, Inc.: Wallingford, CT, 2009.

(48) Foster, J. P.; Weinhold, F. J. Am. Chem. Soc. 1980, 102, 72117218.

(49) Weinhold, F.; Carpenter, J. E. In The Structure of Small Molecules and Ions; Naaman, R., Vager, Z., Eds.; Plenum: New York, 1988; pp 227-236.

(50) Bader, R F W. An Introduction to the Electronic Structure of Atoms and Molecules; Clarke: Toronto; 1970.

(51) Lu, T.; Chen, F. J. Comput. Chem. 2012, 33, 580-592.

(52) Zhurko, G. A. ChemCraft Home Page: a set of graphical tools for facilitating working with quantum chemistry computations (http://www. chemcraftprog.com).

(53) Aquilante, F.; Autschbach, J.; Carlson, R. K.; Chibotaru, L. F.; Delcey, M. G.; Vico, L. D.; Fdez. Galván, I.; Ferré, N.; Frutos, L. M.; Gagliardi, L.; Garavelli, M.; Giussani, A.; Hoyer, C. E.; Manni, G. L.; Lischka, H.; Ma, D.; Malmqvist, P.-Å.; Müller, T.; Nenov, A.; Olivucci, M.; Pedersen, T. B.; Peng, D.; Plasser, F.; Pritchard, B.; Reiher, M.; Rivalta, I.; Schapiro, I.; Segarra-Martí, J.; Stenrup, M.; Truhlar, D. G.; Ungur, L.; Valentini, A.; Vancoillie, S.; Veryazov, V.; Vysotskiy, V. P.; Weingart, O.; Zapata, F.; Lindh, R. J. Comput. Chem. 2016, 37, 506541.

(54) Wolf, A.; Reiher, M.; Hess, B. A. J. Chem. Phys. 2002, 117, 9215-9226.

(55) Roos, B. O.; Taylor, P. R.; Siegbahn, P. E. M. Chem. Phys. 1980, 48, 157-173.

(56) Malmqvist, P.-A.; Roos, B. O.; Schimmelpfennig, B. Chem. Phys. Lett. 2002, 357, 230-240.

(57) Andersson, K.; Malmqvist, P.-Å.; Roos, B. O.; Sadlej, A. J.; Wolinski, K. J. Phys. Chem. 1990, 94, 5483-5488.

(58) Vancoillie, S.; Malmqvist, P.-A.; Pierloot, K. ChemPhysChem 2007, 8, 1803.

(59) Vancoillie, S.; Neese, F.; Rulisek, L.; Pierloot, K. J. Phys. Chem. A 2009, 113, 6149-6157.

(60) Chibotaru, L. F.; Ungur, L. J. Chem. Phys. 2012, 137, 06411222.

(61) Gendron, F.; Páez-Hernández, D.; Notter, F.-P.; Pritchard, B.; Bolvin, H.; Autschbach, J. Chem. - Eur. J. 2014, 20, 7994-8011.

(62) Gendron, F.; Pritchard, B.; Bolvin, H.; Autschbach, J. Dalton Trans. 2015, 44, 19886-19900.

(63) Autschbach, J. Comments Inorg. Chem. 2016, 36, 215-244.

(64) Baerends, E. J.; Ziegler, T.; Autschbach, J.; Bashford, D.; Bérces, A.; Bickelhaupt, F. M.; Bo, C.; Boerrigter, P. M.; Cavallo, L.; Chong, D. P.; Deng, L. Amsterdam Density Functional (ADF), SCM, Theoretical Chemistry; Vrije Universiteit, Amsterdam, The Netherlands, 2014.

(65) Roos, B. O.; Taylor, P. R.; Siegbahn, P. E. M. Chem. Phys. 1980, $48,157-173$.

(66) Malmqvist, P. Å.; Roos, B. O. Chem. Phys. Lett. 1989, 155, 189194.

(67) Angeli, C.; Cimiraglia, R.; Evangelisti, S.; Leininger, T.; Malrieu, J. P. J. Chem. Phys. 2001, 114, 10252-10264.

(68) Ganyushin, D.; Neese, F. J. Chem. Phys. 2013, 138, $104113-$ 104119 .

(69) Neese, F. Wiley Interdisciplinary Reviews: Computational Molecular Science 2012, 2, 73-78.

(70) Pantazis, D. A.; Neese, F. J. Chem. Theory Comput. 2011, 7, $677-684$.

(71) Heyd, J.; Scuseria, G. E.; Ernzerhof, M. J. Chem. Phys. 2003, 118, $8207-8215$

(72) Prodan, I. D.; Scuseria, G. E.; Martin, R. L. Phys. Rev. B: Condens. Matter Mater. Phys. 2007, 76, 033101.

(73) Garza, A. J.; Scuseria, G. E. J. Phys. Chem. Lett. 2016, 7, 41654170. 
(74) Weaver, B. Anal. Chem. 1968, 40, 1894-1896.

(75) Newton, T. W.; Hobart, D. E. J. Nucl. Mater. 2004, 334, 222224.

(76) Rutherford, E.; Soddy, F. Philos. Mag. 1903, 5, 576-591.

(77) Brito, H. F.; Liu, G. K. J. Chem. Phys. 2000, 112, 4334-4341.

(78) Runde, W.; Bean, A. C.; Brodnax, L. F.; Scott, B. L. Inorg. Chem. 2006, 45, 2479-2482.

(79) Sykora, R. E.; Assefa, Z.; Haire, R. G.; Albrecht-Schmitt, T. E. Inorg. Chem. 2006, 45, 475-477.

(80) Burns, J. H.; Peterson, J. R.; Baybarz, R. D. J. Inorg. Nucl. Chem. 1973, 35, 1171-1177.

(81) Phanon, D.; Mosset, A.; Gautier-Luneau. Solid State Sci. 2007, 9, 496-505.

(82) Shannon, R. D. Acta Crystallogr., Sect. A: Cryst. Phys., Diffr., Theor. Gen. Crystallogr. 1976, 32, 751-767.

(83) Sykora, R. E.; Assefa, Z.; Haire, R. G.; Albrecht-Schmitt, T. E. J. Solid State Chem. 2004, 177, 4413.

(84) Cross, J. N.; Villa, E. M.; Wang, S.; Diwu, J.; Polinski, M. J.; Albrecht-Schmitt, T. E. Inorg. Chem. 2012, 51, 8419-8424.

(85) Cary, S. K.; Vasiliu, M.; Baumbach, R. E.; Stritzinger, J. T.; Green, T. D.; Diefenbach, K.; Cross, J. N.; Knappenberger, K. L.; Liu, G.; Silver, M. A.; DePrince, A. E., III; Van Cleve, S. M.; House, J. H.; Kikugawa, N.; Gallagher, A.; Arico, A. A.; Dixon, D. A.; Polinski, M. J.; Albrecht-Schmitt, T. E. Nat. Commun. 2015, 6, 6827-6834.

(86) Polinski, M. J.; Garner, E. B., III; Maurice, R.; Planas, N.; Stritzinger, J. T.; Parker, T. G.; Green, T. D.; Alekseev, E. V.; Van Cleve, S. M.; Depmeier, W.; Gagliardi, L.; Shatruk, M.; Knappenberger, K. L.; Liu, G.; Skanthakumar, S.; Soderholm, L.; Dixon, D. A.; Cross, J. N.; Albrecht-Schmitt, T. E. Nat. Chem. 2014, 6, 387-392.

(87) Ibers, J. A. Acta Crystallogr. 1956, 9, 225-231.

(88) Bray, T. H.; Ling, J.; Choi, E. S.; Brooks, J. S.; Beitz, J. V.; Sykora, R. E.; Haire, R. G.; Stanbury, D. M.; Albrecht-Schmitt, T. E. Inorg. Chem. 2007, 46, 3663-3668.

(89) Larson, A. C.; Cromer, D. T. Acta Crystallogr. 1956, 9, 10151018.

(90) Larson, A. C.; Cromer, D. T. Acta Crystallogr. 1961, 14, 128132.

(91) Pauling, L. The Nature of the Chemical Bond; Cornel: Ithaca, NY, 1948.

(92) Xu, J.; Radkov, E.; Ziegler, M.; Raymond, K. N. Inorg. Chem. 2000, 39, 4156-4164.

(93) Penneman, R. A.; Ryan, R. R.; Rosenzweig, A. Acta Crystallogr., Sect. B: Struct. Crystallogr. Cryst. Chem. 1974, 30, 1966.

(94) Shuller-Nickles, L. C.; Ewing, R. C.; Becker, U. J. Solid State Chem. 2013, 197, 550-559.

(95) Cary, S. K.; Ferrier, M. G.; Baumbach, R. E.; Silver, M. A.; Lezama-Pacheco, J.; Kozimor, S. A.; La Pierre, H. S.; Stein, B. W.; Arico, A. A.; Gray, D. L.; Albrecht-Schmitt, T. E. Inorg. Chem. 2016, 55, 4373-4380.

(96) Cross, J. N.; Duncan, P. M.; Villa, E. M.; Polinski, M. J.; Babo, J.M.; Alekseev, E. V.; Booth, C. H.; Albrecht-Schmitt, T. E. J. Am. Chem. Soc. 2013, 135, 2769-2775.

(97) Lin, J.; Cross, J. N.; Diwu, J.; Meredith, N. A.; Albrecht-Schmitt, T. E. Inorg. Chem. 2013, 52, 4277-4281.

(98) Diwu, J.; Wang, S.; Grant, D. J.; Gagliardi, L.; Albrecht-Schmitt, T. E. Inorg. Chem. 2012, 51, 6906-6915.

(99) Diwu, J.; Nelson, A.-G. D.; Wang, S.; Campana, C. F.; AlbrechtSchmitt, T. E. Inorg. Chem. 2010, 49, 3337-3342.

(100) Nelson, A.-G. D.; Bray, T. H.; Zhan, W.; Haire, R. G.; Sayler, T. S.; Albrecht-Schmitt, T. E. Inorg. Chem. 2008, 47, 4945-4951.

(101) Carnall, W. T. J. Chem. Phys. 1992, 96, 8713-8726.

(102) Cary, S. K.; Silver, M. A.; Liu, G.; Wang, J. C.; Bogart, J. A.; Stritzinger, J. T.; Arico, A. A.; Hanson, K.; Schelter, E. J.; AlbrechtSchmitt, T. E. Inorg. Chem. 2015, 54, 11399-11404.

(103) Jursich, G. M.; Beitz, J. V.; Carnall, W. T.; Goodman, G. L.; Williams, C. W.; Morss, L. R. Inorg. Chim. Acta 1987, 139, 273-274.
(104) Sykora, R. E.; Deakin, L.; Mar, A.; Skanthakumar, S.; Soderholm, L.; Albrecht-Schmitt, T. E. Chem. Mater. 2004, 16, 1343-1349.

(105) Schilder, H.; Lueken, H. J. Magn. Magn. Mater. 2004, 281, 1726.

(106) Speldrich, M.; Schilder, H.; Lueken, H.; Kogerler, P. Isr. J. Chem. 2011, 51, 215-227.

(107) van Leusen, J.; Speldrich, M.; Schilder, H.; Kögerler, P. Coord. Chem. Rev. 2015, 289-290, 137-148.

(108) Gorller-Walrand, C.; Binnemans, K. Rationalization of crystalfield parameterization. In Handbook on the Physics and Chemistry of Rare Earths; Gschneidner, K.A., Eyring, L., Eds.; Elsevier: Amsterdam, 1996; Vol. 23, pp 121-130.

(109) Wybourne, B. G. Spectroscopic Properties of Rare Earths; Wiley: New York, London, Sydney, 1965.

(110) Liu, G. K.; Carnall, W. T.; Jursich, G.; Williams, C. W. J. Chem. Phys. 1994, 101, 8277-8289.

(111) Shuskus, A. J. Phys. Rev. 1962, 127, 2022-2024.

(112) Tanner, P. A.; Kumar, V. V. R. K.; Jayasankar, C. K.; Reid, M. F. J. Alloys Compd. 1994, 215, 349-370.

(113) Gendron, F.; Autschbach, J. J. Phys. Chem. Lett. 2017, 8, 673678 .

(114) Coutinho, J. T.; Antunes, M. A.; Pereira, L. C. J.; Bolvin, H.; Marçalo, J.; Mazzanti, M.; Almeida, M. Dalton Trans. 2012, 41, 13568.

(115) Ungur, L.; Van den Heuvel, W.; Chibotaru, L. F. New J. Chem. 2009, 33, 1224-1230. 